\title{
التصميم المستدام لتنسيق المواقع الأثرية والارتقاء بها واستثمارها
}

\section{Sustainable Design of the Urbanization and Investment of Archaeological} Sites

\author{
أ. م. د/ دينا فكري جمال إبراهيم

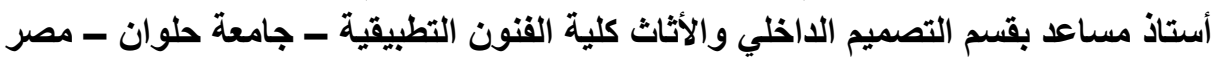

\section{Assist. Prof. Dr. Dina Fekry Gamal}

Assistant Professor, Department of Interior Design and Furniture, Faculty of Applied

Arts - Helwan University - Egypt

dinafekry@hotmail.com

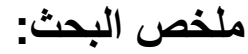

تعكس المواقع الأثرية إرث الثتعوب و إنجاز اتها الثقافية والحضارية، فهي المكان الذي أثبت أصالته في مقاومة قوى التغيير، وهي المرجع البصري للطابع المعماري المميز لتلك المجمعات، وتتتكل المواقع الأثرية بمصر من مستويات متباينة نتيجة المخزون التراثي المعماري والحضاري التي تحظى به بداية من العمارة المصرية القديمة ومرورا بعصور الإغريق والرومان ثم العمارة الإسلامية بداية من مسجد عمر بن العاص وعمارات العصر الأموي والطولوني و الإخشيدي و الفاطمي والأيوبي و المملوكي والعثماني، ثم عمارة نهضة مصر"محمد علي باشا" المززوجة بالتأثير الأوروبي، مما يستوجب الإستفادة من ذلك المخزون وتوظيفه كأداة فعالة في التطوير والإبداع التشكيلي والمعماري

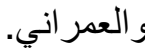
وفي النصف الاخير من القرن العشرين ظهرت العديد من الاتجاهات التي تنادي بالحفاظ على المواقع الأثرية والارتقاء بها واستثمار ها و الوقوف على المؤثرات السلبية المسببة لتدهور حالتها نتيجة غياب الوعي و الإهمال والتعديات و الفوضى بين المباني و البيئة المحيطة ، فالمو اقع الأثرية تقع في محيط حيوي نابض وعمران قائم، مما يوجد نوع من التفاعل بين

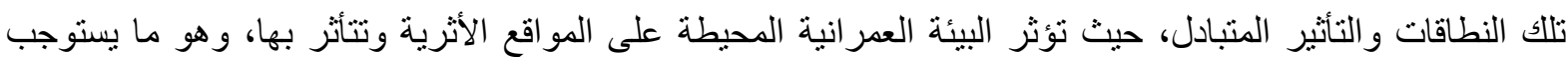
الوعي بمدخلات البيئة العمر انية المحيطة وعلاقتها بتلك المو اقع باعتبار ها أحد المؤثرات الهامة التي تغير من حالة الأثر. ومن هنا تتضح مشكلة البحث والتي تتلخص في: يو اجه تتسيق المواقع الأثرية حالة من التدهور و الاهمال الناتج عن عدة بهن مشاكل منها ما يتعلق بالعامل البشري ومنها ما هو ناتج عن سوء التخطيط و التنظيم، مما يكون له بالغ الأثر في فقدان

$$
\text { الارث و التراث وبالتالي فقدان الهوية والأصالة. }
$$

لذا يهذف البحث إلى: تقديم حلول تصميمية مستدامة لتنسيق المواقع الأثرية دورها الأساسي هو التنمية والارتقاء بتلك المو اقع، و استثمار ها ثقافيا، واجتماعيا، و اقتصاديا.

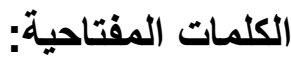
التصميم الكستدام - تتسيق المواقع الأثرية ـ الحفاظ والارتقاء بالمو اقع الأثرية ـ استثمار المو اقع الأثرية

\begin{abstract}
:
The archaeological sites are believed to be the reflection of people heritage, cultural and civilizational achievements. As they are the places that has proven its authenticity in resisting the forces of change. It is also the visual reference to the distinctive architectural character of these societies. The archaeological sites in Egypt are formed of different levels as a result of
\end{abstract}


the architectural and cultural heritage stock, which starting from ancient Egyptian architecture, passing through Greek and Roman ages, and ending by Islamic architecture. Starting from Amr ibn al-Ass Mosque and the buildings of Amawy, Toulon, Akchidi, Fatimi, Ayyuby, Mamluk and Othmanly, and then the architecture of the Egyptian renaissance of "Muhammad Ali Pasha" mixed with European influence. Thus, necessitates promoting and engaging of all these, as an innovative and effective tool in the architectural and creative urban expansion.

In the second half of the $20^{\text {th }}$ century, there were many trends which demanded for the preservation, upgrading and investment of archaeological sites and identifying the negative impacts causing their deterioration, as a result of the lack of awareness, neglect, encroachments and chaos between buildings and the surrounding environment. Archaeological sites are located in a vibrant and urban environment, which creates a kind of interaction between those ranges and mutual influence.

Hence, this research aims to propose a variety of sustainable design solutions for the urbanisation of archaeological sites that fosters growth and investment of it culturally, economically, and socially.

\section{Keywords:}

Sustainable Design; Archaeological Sites; Investment of Archaeological Sites; Urbanisation of Archaeological Sites; Preserving and Inhancing of Archaeological Sites.

يعد التراث الحضاري و الثقافي الذي تمتلكه مصر أحد مظاهر الاعتزاز والفخر بين دول العالم، نظراً لتفردها بهذا التراث، بجانب قيمته وأصالته المتميزة. وقد اتجهت مصر إلى الحفاظ علي هذا التراث من خلال الحفاظ علي المواقع

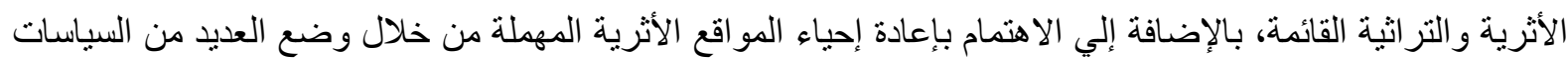

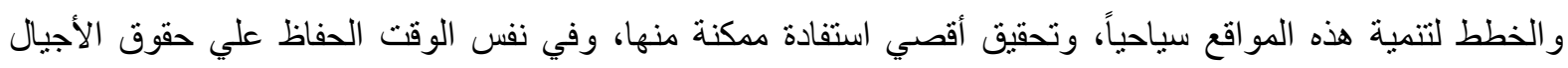

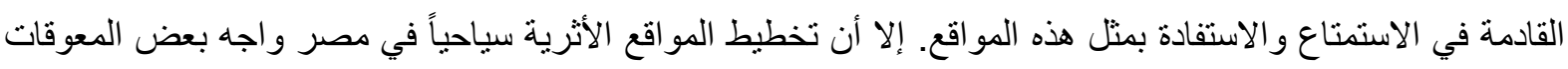

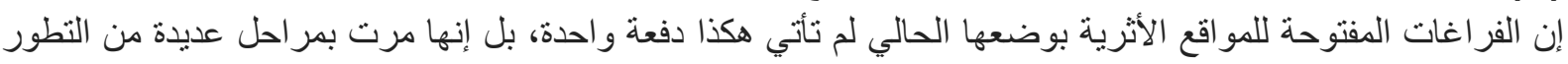

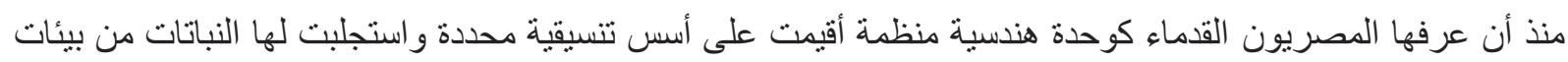

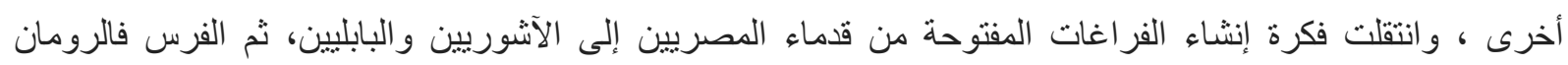

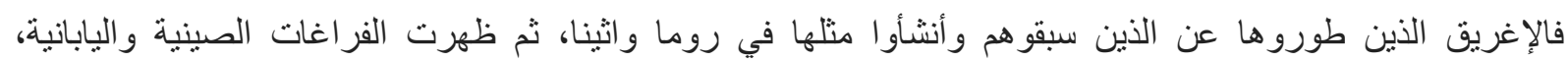

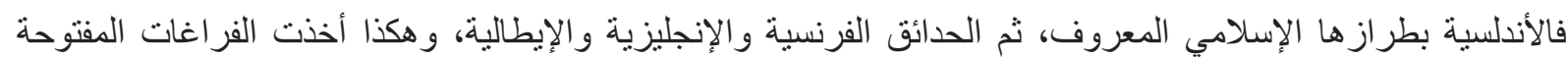
تتطور بشكل سريع ومتلاحق وتزداد أعدادها وأهميتها، ويتطور معها فن التصميم والتنسيق حتى وصلنا الإنى الإنى الاتجاه

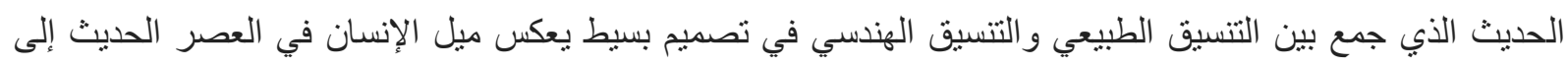




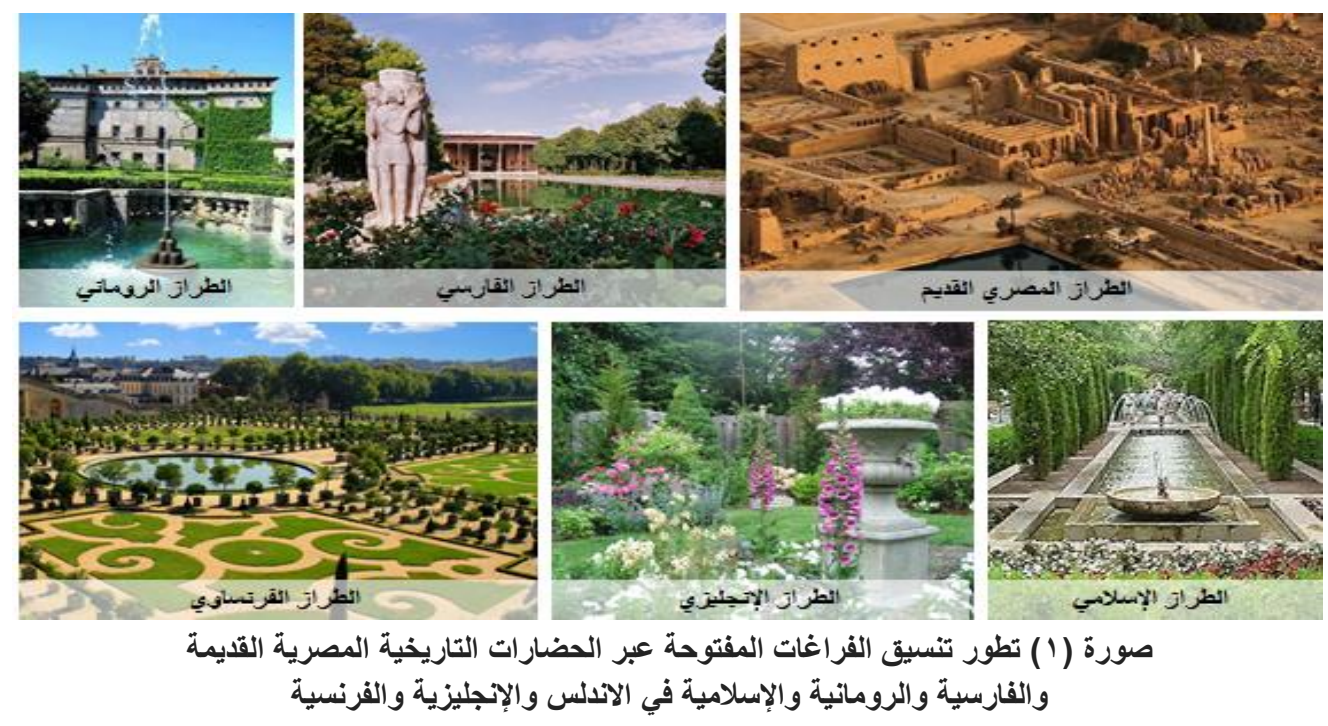

تطور تصميم الفراغات المفتوحة للمواقع الاثرية عبر الحضارات من منظور الفكر الحاكم:

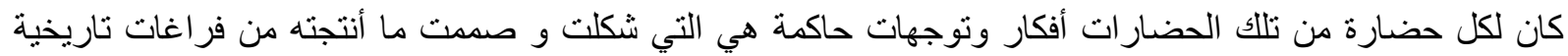
اختلفت من مجتمع إلى مجتمع ومن عصر إلى عصر، علما بأن هذه التأثيرات تفاوتت بين القوة و الضعف فكانت نتيجة لما أفرزته تللك المجتمعات من فكر و ثقافة من ناحية، أو سياسات وتوجهات معينة من ناحية أخرى.

\section{الاتجاه الاينى و العقائدي:}

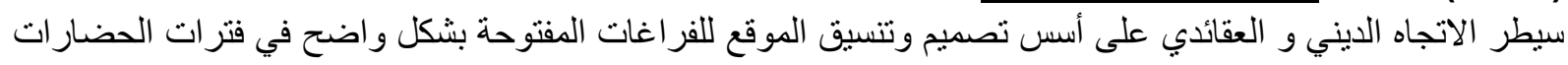

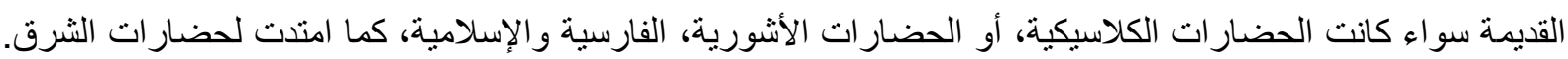
حيث انعكست أسس و مفاهيم العقيدة على تصميم الفر اغات المفتوحة معبرة بذلك عن التكامل بين الدين و الدنبا[ []، وكان الغرض الأساسي منها هو غرض ديني عقائدي بحت، حيث كانت تلحق بالمعابد في الحضارة المصرية القديمة. أما

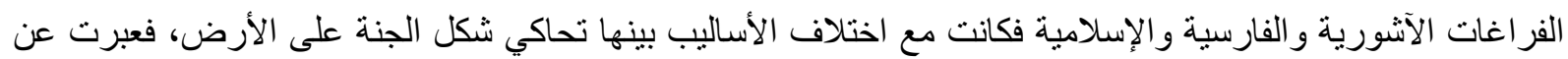

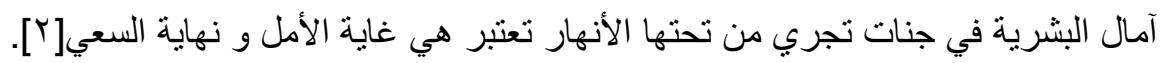

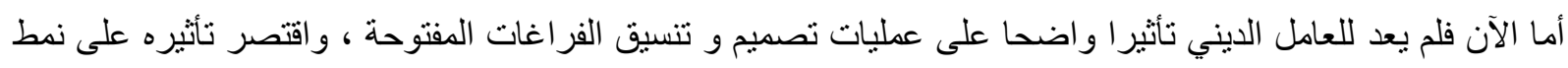
بعض الفر اغات المفتوحة التي تتبع طر ازا معينا ، بحيث تنقل المفردات أو الأفكار دون وجود مرجعية عقائدية لها.

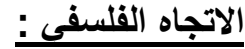

ارتبط الاتجاه الفلسفي بالدين و العقيدة في الحضار ات القديمة و الحضارة الإسلامية و حضار ات الثرق التي جاءت فيها الفر اغات المفتوحة مماتلة لمذاهب فلسفية متنوعة تتبع كل عقيدة. و من ثم تمثلت فلسفة تصميم الفراغات المفتوحة في عصر النهضة في محاكاة الطبيعة بهدف الوصول إلى الكمال المطلق. وفي القرن الثامن عشر ظهرت فلسفات أكثر تعمقا تدعو إلى الأخذ بمظاهر الطبيعة من حيث تراكيبها وتتسيقاتها الفطرية و ذللك للتنفيس عن الضغوط الو اقعة على الإنسان[ب] ومن ثم كان عصر الحداثة بنظرياته و الفلسفة التي تحكمه و التطور التكنولوجي و الصناعي الذي يميزه، و تبعه فترة ما بعد الحداثة، حيث نادي المصممون بالعودة للطبيعة. وتعتبر المرحلة الحالية مرحلة يعتمد فيها التصميم على الفكر الفلسي و الذي تبلور في صورة توجيهات فردية وأراء شخصية و التي تهدف في كثير من الأحبان إلى الرغبة في التميز. 
كان ظهور الفكر الوظيفي بشكل واضحح وصريح لأول مرة في فترات العصور الوسطى حيث خضع تصميم وتنسيق الفر اغات المفتوحة لاعتبار ات وظيفية استخدمت لتحقيق أغر اض و أهداف محددة كإنتاج الخضراوات و الفو اكه ـ التحقيق

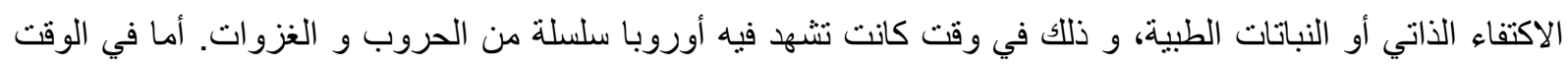
الحالي فقد تطور الفكر الوظيفي و اتسع مفهومه ليشمل الجوانب الإنسانية و النفسية و الجمالية و البيئية، أب أنه لنجاح أب ولي تصميم لابد وأن يؤدي الغرض الوظيفي له في نطاق البيئة المحيطة لتلبية رغبات و احتياجات المستخدمين مع تحقيق الجو انب البصرية و الجمالية، دون تعارض أحد هذه الجو انب مع الأخرى[بــ.

\section{الاتجاه الابداعى:}

الرغبة في التميز والإبداع من الاتجاهات التي ظهرت منذ القدم و لو أنها ارتبطت بأعمال جماعية بعيدا عن التفرد حيث

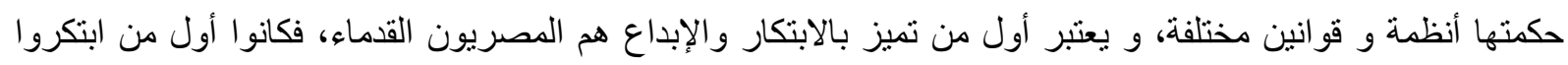

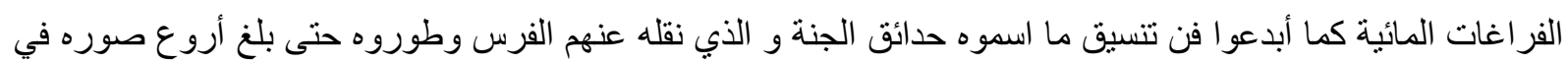
تاريخهم. و من ثم كان عصر النهضة الأوروبي عصر ا ذهبيا تبارت فيه الدول الأوروبية و تسابقت على التميز في تتسيق و تصميم الفراغات المفتوحة. فمن فرنسا نبغ المبدع أندريه ليونتر و صمم الفراغات المفتوحة فرساي الثهيرة، و المصدم الإنجليزي تيودور الذي سمي الطراز التيودوري على اسمه حيث تميز بتشكيلات العنصر النباتي، و في إيطاليا التي

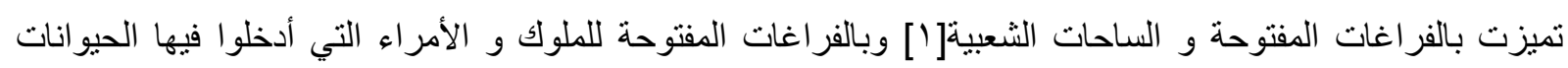
المفترسة و أقفاص الطيور النادرة فظهرت حدائق الحيوان لأول مرة في العالم. ومما لا شك فيه أن المرحلة الحالية هي مرحلة التحرر حيث وصل الفكر الإبداعي إلى ذروته معتمدا على التطور التكنولوجي و الفكري والتقنى، والتطور في الأراء والنظريات، بالإضافة إلى تضافر جهود الدصممين، مما يجعل الفكر الإبداعي فكر ا مسيطر ا على العملية التصميمية يحكمه رغبة في ولئ التمبز و والتفرد.

\section{الاتجاة الاقتصادي :}

يعتبر الاتجاه الاقتصادي اتجاه حديث، بدا تأثثره على تصميم و تتسيق الفراغات المفتوحة في أعقاب الثورة الصناعية في

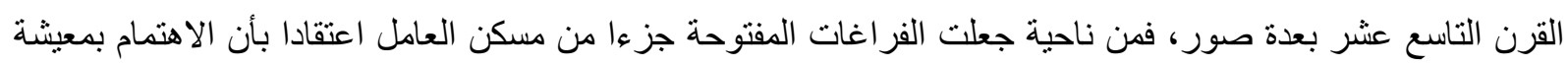
العامل يساعد على زيادة الإنتاج ويساهم في إنجاح عملية إنتاج الجملة. و من ناحية أخرى فإنه مع بدايات النصف الثاني من القرن العشرين ظهرت الإناجت فكرة إنثاء المنتزهات و الفر اغات المفتوحة العامة ذات الملكيات الخاصة بهدف اقتصادى بحت، و تعتمد تلك المتنز هات في تصميمها على التميز و الإبهار وتتأثر في ذللك بالاتجاه الإبداعي الذي أشرنا إلبه وذلك بهدف الجذب الجماهيري لزيادة العائد المادي.[؛]

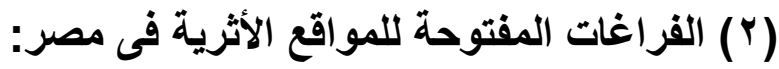

يوجد في أغلب المدن القديمة المعاصرة حضار ات وبيئات تراثية ومباني أثرية سبقتها وساعدت في تحديد شخصيتها وطابعها الحضاري، وقد تنوعت الفراغات المفتوحة في مصر ما بين مساحات شاسعة من الحدائق والبساتين العامة و الخاصة و المتحفية والنوعية المتخصصة، ولم يضاف إليها إلا القليل، وقد شوهت ودمرت فى الفترة الأخيرة عدة حدائق

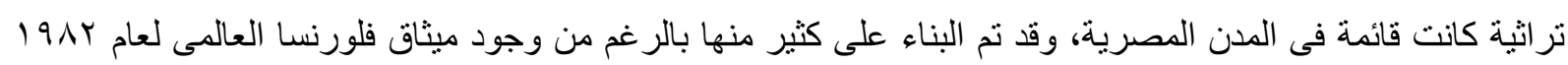
لكيفية التعامل مع الحدائق التراثية واحتر امها، وقد وقعت عليه مصر. وييرز هذا الميثاق سمو النظرة العالمية للحدائق 
التر اثية و التاريخية وكيفية التعامل معها من ناحية الصيانة و الحفاظ و الترميم و التجديد، وتنظيم استخدامها وحسن الانتفاع

بها، و الإجر اءات القانونية والإدارية للحفاظ عليها باعتبار ها نراث إنسانى حى على المستويين القومى أو العالمى [0]. و البيئة التراثية تحتوي علي مباني و علاقات وذكريات مثر اكمة ومنوارثة كما نوجد بالبيئة التراثية عناصر إنسانبة ومادية

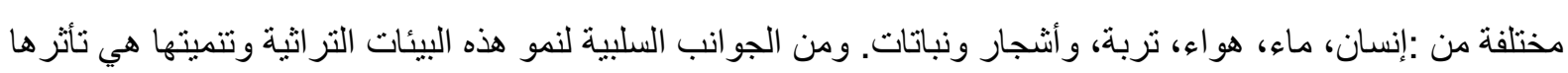
بكل التغيير ات الغير مدروسة مما يفقدها القدرة علي الاستدامة، فتركها بدون تنمية يمكن أن يؤدي إلي فقدها.

( - ا ( ) المشاكل التي تتعرض لها الفراغات المفتوحة للمواقع الأثرية في مصر:

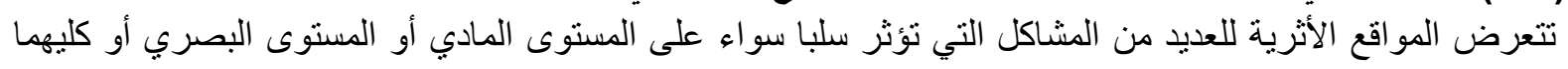

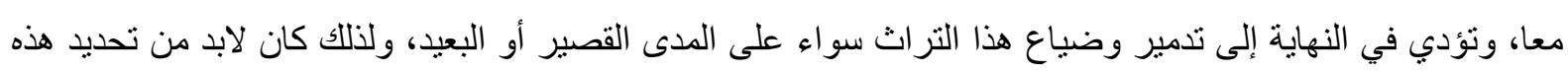

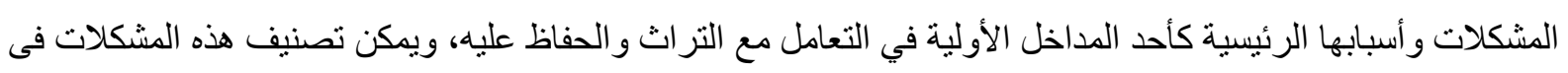
العناصر التالية:

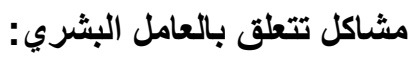

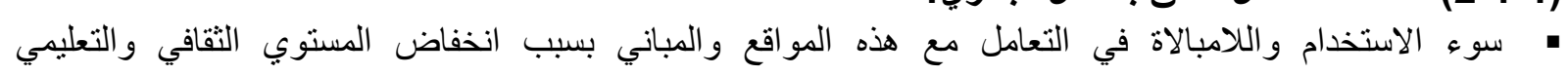

$$
\text { و الحضاري لساكني هذه المناطق. }
$$

" التأثير السلبي علي الصورة البصرية المنكاملة وتغيير شخصية المبني كجزء من العمر ان المحيط كما في صورة(ب).

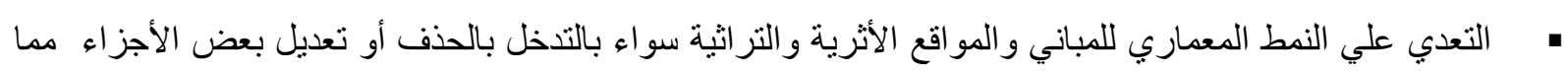
يغير من طابعها المميز. إضافة المستحدثات التكنولوجية مثل وحدات التكييف أو ما شابه من إعلانات ضوئية وخلافه. هإهمال أعمال الصيانة الدورية للازمة للحفاظ على هذه المباني نتيجة انخفاض المستوي الاقتصادي للسكان و عدم إعلاني
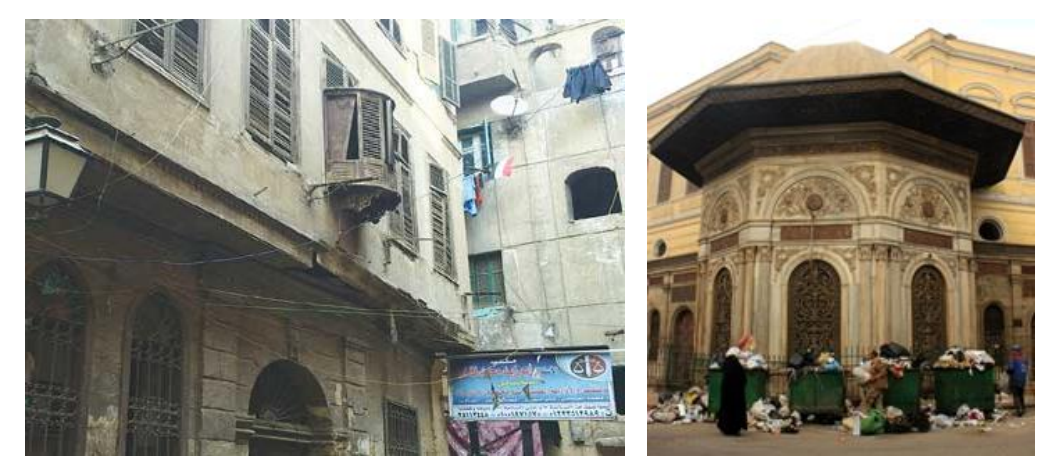
قدرتهم على تحمل نفقات الصيانة العالية.

صورة(r) يوضح صور تعدي العنصر البشري على المناطق الاثرية الناتج عن قصور وانعام الوعي بالأهمية التاريخية والتراثية والجمالية

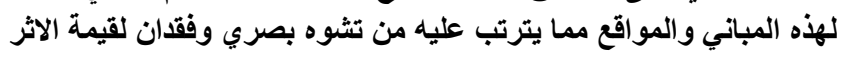

مشاكل بيئية:

• تذبذب منسوب المياه الجوفية وما له من تأثير علي أساسيات المباني والمواقع الأثرية، مما يؤدي إلي حدوث هبوط لبعضها ويمثل خطر ا= كبير ا= عليها. • عدم مقاومة بعض المواد المستخدمة بالمبني للغازات والأثربة و الفطريات و البكتريا،مما يعرضها للتلف بصورة تهدد سلامة المبني عند تفاقمها. 

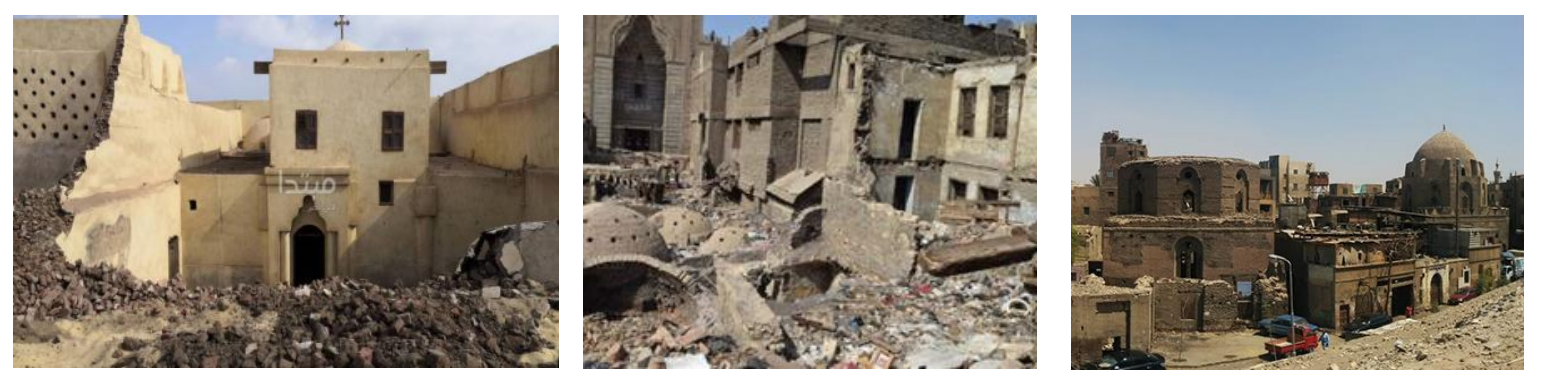

صورة (r) الهام والتلف من اكبر المشاكل التي تواجه المواقع الاثرية سواء بسبب المشاكل البيئية

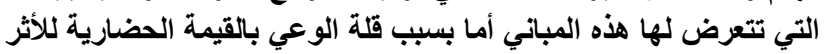

مشاكل إقتصادية:

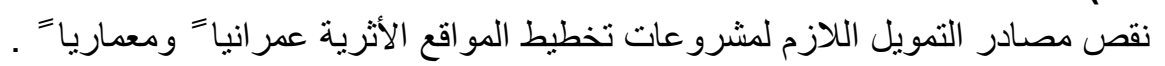

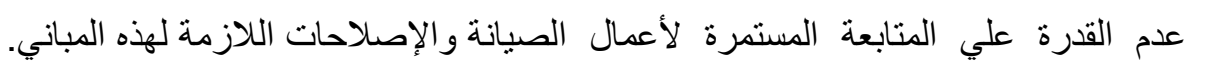

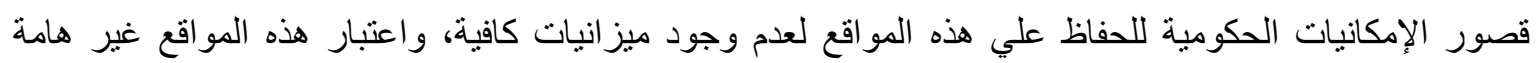

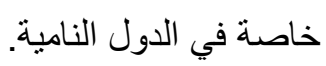
ا الإهمال الحكومي لهذه المباني و عدم الإثر اف الحكومي الكامل و اللازم لحمايتها.

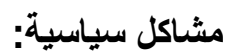

هياب القو انين و التثريعات اللازمة للحفاظ علي الأبنية الأثرية وخاصة فيما يتعلق بالعمر ان المحيط.

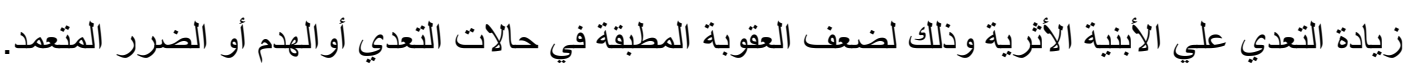

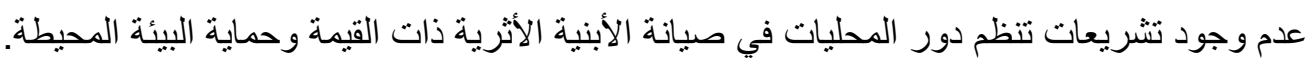

عدم وجود قو انين وتثريعات خاصة بتنظيم أعمال البناء حول المو اقع الأثرية و التر اثثية و التاريخية.

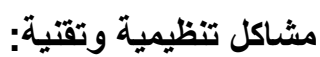

عدم وجود الأجزة الفنية المؤهلة والمدربة القادرة علي تتفيذ أو متابعة تنفيذ مشاريع الحفاظ علي الهناطق الأثرية.

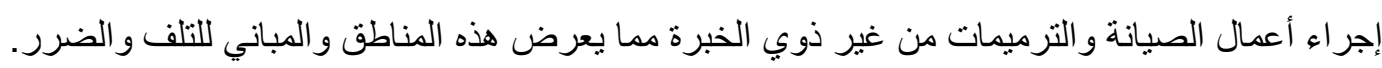
" عدم وجود هيئات ومعاهد فنية متخصصة في تخريج العاملين بالترميم المعماري.

(r) الحفاظ للارتقاء والاستثمار بالفراغات المفتوحة للمناطق التاريخية والمواقع الأثرية: يعد الحفاظ على تلك المواقع الاثرية حلا للمشكلات السابق ذكرها، إلا أن الحفاظ يجب أن النارئ يتمد على مدخلين أساسيين

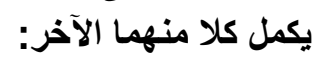

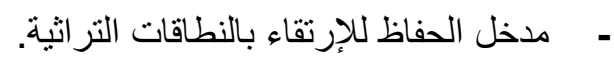

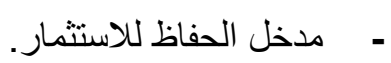
ويقصد بالحفاظ انه عمل يتخذ لمنع التدهور والتثويه بالمدن القديمة أو البيئة التاريخية أو المباني الثراثية ويضم كافة

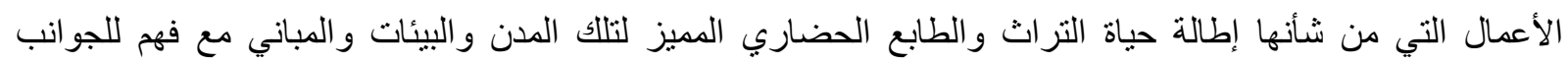

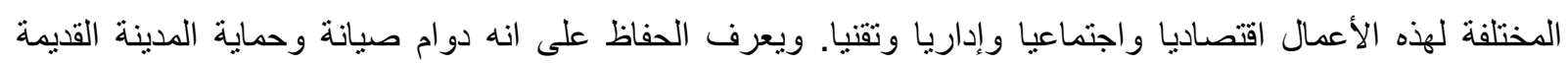

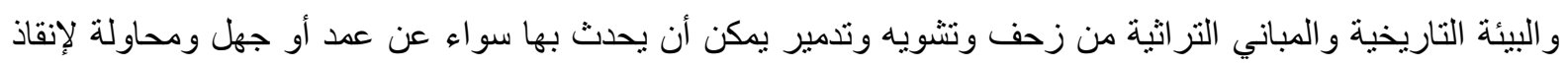

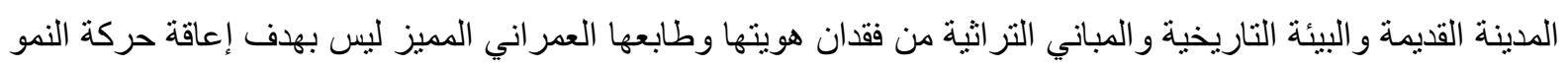


و التطور و التقدم ولكن على أساس أن الجديد يجب أن يكون استمرارا للثخصية الأصلية للمحتوى التراثي والتاريخي،

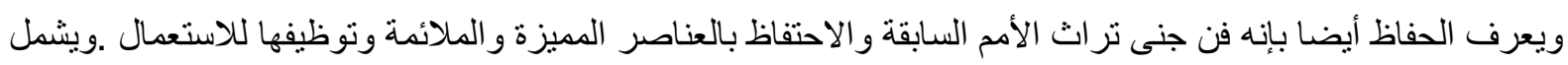

الحفاظ مجمو عة العمليات الآتية :الإصلاح و الترميم ، الحماية ، إعادة التأهيل، إعادة التوظيف، و والتجديد الثامل.

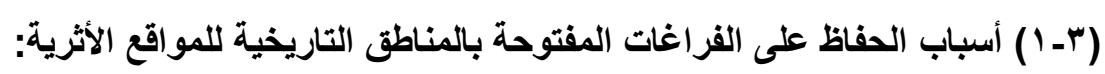

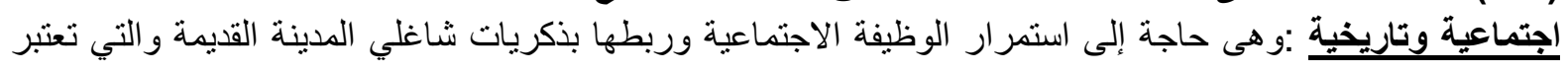

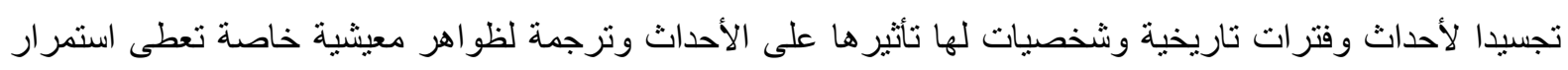
للنبع الحضاري عبر العصور. اقتصادية: تعتبر الوظيفة السياحية للتراث العمر اني مصدر هام للاخل مع إمكانيات إعادة استخدام المناطق المحافظ عليها

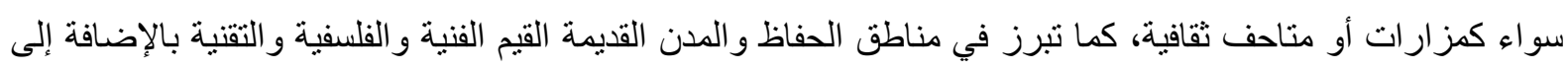

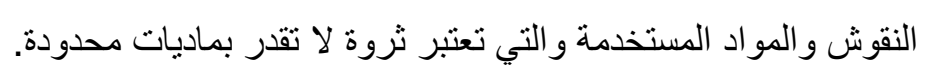
سياسية: من خلال الحفاظ يمكن التعلم من الماضي وسرد التاريخ بأحداثه العظيمة وتعبيرا عن الحالة السياسية المسيطرة على المدن في تللك الفترات، وعن قيم الحكم ورسوخه وقوته و استقراره. دينية وعقائدية :وتتمثل في وضع القيم الدينية في المجمو عات العمر انية من دور عبادة ومساكن و أسو اق و غير ها.

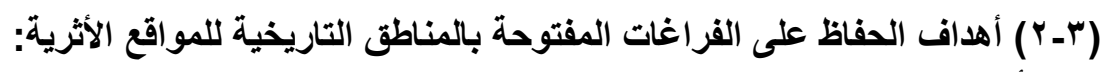

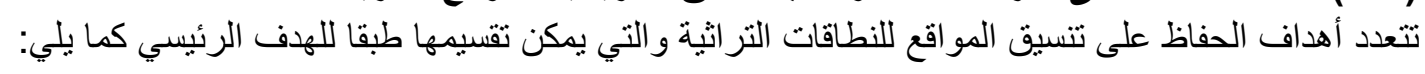
أولا :الأهداف الجمالية والرمزية: وقاية النطاقات التراثية من عوامل التدهور ، وما يترتب عليه من الحفاظ على شخصية المدينة بمناطقها ومبانيها القديمة

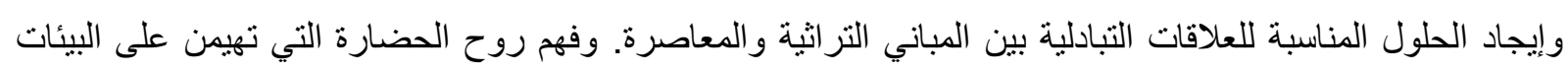

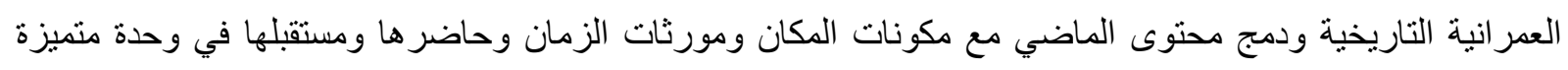
تعطى الإحساس بالاستمر ارية.

ثانيا :الأهداف التاريخية والثقافية: الحفاظ على الإستمر ارية الحضارية بغرض توصية الإنيل الرسائل و المعاني الفنبة و الثقافية و الإنسانية و الحضارية التي تحنويها المدن القديمة والبيئات التاريخية والمباني التراثية عبر الأجيال القادمة بصورة جيدة، وعدم إحداث فجوة في إستمر ارية المدينة كثخصية منطورة والحفاظ على التسلسل التاريخي لها، كذلك الحفاظ على نسيج عمر اني متميز يمثل تر اكمات الإبداع الإنساني عبر العصور.

ثالثا :الأهداف الإقتصادية: تنمية الموارد السياحية، وتوفير جزء الإية: من الموارد المالية اللازمة لتمويل برامج الحفاظ والصيانة، وإعادة الحياة للمبانى التراثية.

رابعا :الأهداف الإجتماعية: الحث على تنمية وتطوير الوعي بأهمية الجذور التاريخية التراثية والأسلوب الأمثل للتعامل معها، وتطوير برامج المشاركة الثعبية وتشجيع الجهود الذاتية للحفاظ على الطابع الحضاري وحماية المباني الأثرية والتركيز على الآثار و ماحولها من مباني ذات طابع مميز. 
و التأكيد على أن ليس الهدف هو الحفاظ الوقاية والصيانة فقط أو استغلال البيئات العمرانية التاريخية سياحيا، ولكن لابد

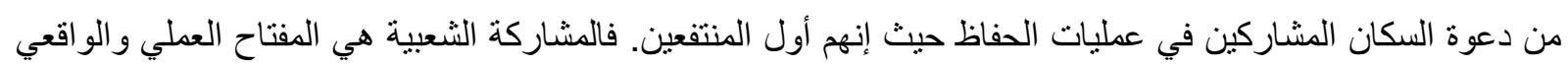
لكافة عمليات الحفاظ.

(r-r ( أسس ومعايير الحفاظ على الفراغات المفتوحة بالمناطق التاريخية للمواقع الأثرية:

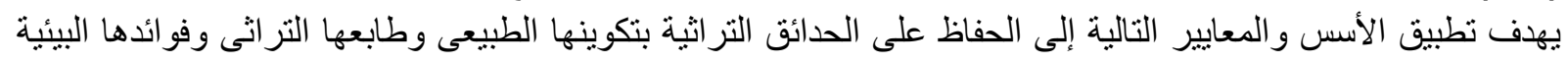
ورسالتها الثقافية كما يلي:

1- يحظر التعدى على أى جزء من الحديقة أو استغلالها فى غير أغراضها الأصلية.

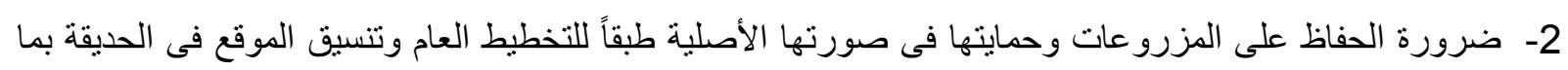
يتطلبه ذلك من تعويض المزرو عات المتحللة أو التالفة. 3- يجب الحفاظ على العناصر المعمارية والإرشادية والمكونات الزخرفية والجمالية القائمة وعناصر المباه الجارية و المتحركة والثابتة كالنافورات و الثنالات أو الأحواض ....و غير ذلك، طبقاً لطابعها الأصلي. 4- عدم عزل الحديقة التراثية عن محيطها المبانشر سواء كان عمرانى حضرى أو ريفى أو طبيعي. 5- توثيق وتسجيل الحديقة التراثية بمر احلها التاريخية وعمل أرشيف للحدائق التر اثية بكل محافظة. 6- القيام بأعمال الحفاظ الو اجبة من صيانة وتئة وترميم وتجديد دورياً. 7- تنفيذ جميع عمليات الحفاظ والترميم والصيانة كل فى مجاله طبقاً للأصول العلمية وتحت إثراف خبراف ومتخصصين. 8- يجب أن تأخذ عمليات الصيانة والحفاظ والترميم للحدائق التراثية أولوية على استعمالات الجمهور، كما يجب أن تخضع زيارتها للضوابط الصارمة التى تهدف فى المقام الأول إلى الحفاظ على روح المكان الممبثقة من شخصيته وأصالته.

9- يجب على الجهات المعنية نوفير الاعتمادات المالية اللازمة لتنفيذ الأسس و المعايير السابقة.

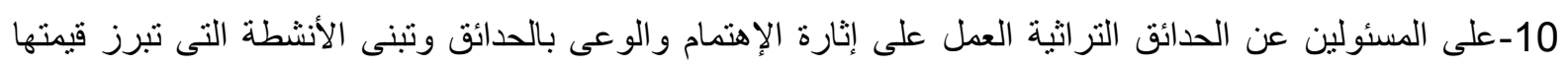

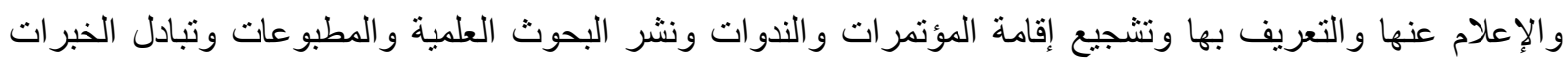
و المعلومات.

\section{(؛ ) استدامة الفراغات المفتوحة وتنسيق المواقع الخارجية:}

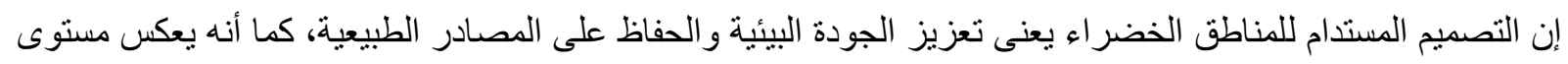
عالى من الكفاية الذاتية. وتحقق معايير الإستدامة للمناطق الخضراء العديد من الفو ائد منها جمال المظهر، وتقليل التدهور البيئى، و إستخدام أكثر

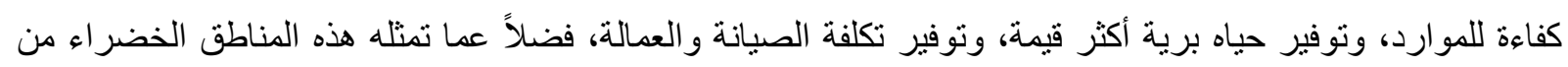

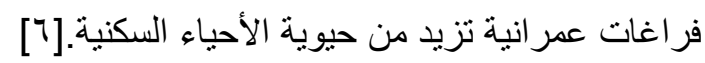
و هو التخطيط و التصميم لهذه المو اقع بما يحقق كل من الإستدامة الأيكولوجية والإجتماعية والإقتصادية، ويعتبر التصميم مستداما عندما يحقق مجمو عة من الأهداف الأساسية التى تجعله يتسم بالكفاءة التصميمية. 


\section{( ـ - ( ) أهداف التصميم المستدام للفراغات المفتوحة وتنسيق المواقع الخارجية: أهداف التصميم المستدام للقر اغات المفتوحة}

\begin{tabular}{|c|c|c|c|c|}
\hline أهداف بيئية & أهداف كثائة & أهداف الوظيقية & أهداف إقتصادية & أهداف بصرية \\
\hline
\end{tabular}

\section{أهداف بصرية:}

(4-1-1)

وتتحقق عندما يستطيع المصمم الوصول إلى تصميم يثير البهجة من الناحية البصرية والتكامل مع باقى الأهداف الأخرى

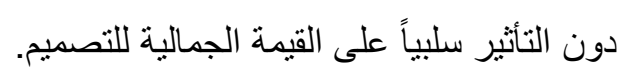
أهداف الكفاءة الإقتصادية:

وتتأثر هذه الأهداف بأنواع النباتات المستخدمة، وعناصر التنسيق المبنية المستخدمة، وكذلك جودة كل منها، وتتحقق هذه الأهداف عندما يوضع فى الإعتبار أثناء التصميم كل من التكلفة قصيرة المدى وطويلة المدى معاً مع الأخذ فى الإعتبار تكلفة الصيانة المستقلية أيضاً، كما يجب توظيف المنتجات المحلية في عناصر ومكونات التنسيق لدعم هذه المنتجات

وضمان استمر اريتها.

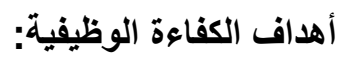

وتتحقق من خلال أداء الأنشطة المختلفة داخل الموقع كالحركة والعمل و الترفيه وغير ها من الأنشطة التى يمكن أن تحدث داخل المواقع، وذلك بكفاءة وبمساعدة عناصر التصميم المختلفة المستخدمة فى تصميم الموقع، مع ضرورة مراعاة الإحتباجات المادية و المعنوية الفعلية للأطفال و المسنين وذوى الإحتياجات الخاصة و المر أة وجميع فئات المجتمع.

\section{أهداف كفاعة الصيانة:}

ترنبط أهداف تحقيق الكفاءة عموماً بتحقيق الكفاءة فى أعمال الصيانة، فنقليل الجهد المستخدم فى الصيانة يقلل تكلفة العمالة المستخدمة و يجعلها أكثر سهولة من خلال تقليل الحاجة إلى إستخدام المخصبات ومقاومات الآفات والمعدات و إستنهلاك المياه.

\section{أهداف بيئية:}

وتتحقق من خلال الإختيار المناسب للنباتات فى المواقع المناسبة لها، وذلك فضلاً عن مراعاة عناصر التصميم الأخرى

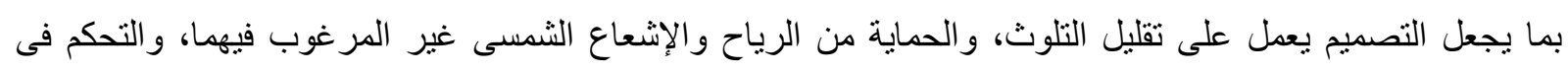
درجة الرطوبة، وتنظيم حركة الهو اء، وتقليل الضوضاء، وتوفير الهواء الجيد، مع التقليل من عوامل التعرية، مع التنأثير والثير

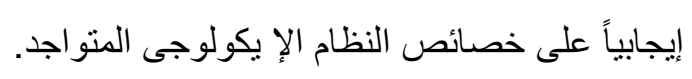

( ع - r ) مبادئ التصميم المستدام للفراغات المفتوحة وتنسيق المواقع الخارجية:

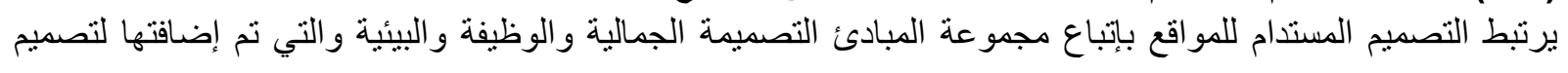
المو اقع ليحقق الإستدامة بشكل أكثر فاعلية، حيث أصبح الهدف هو الوصول لمواقئ اقع صديقة للبيئة تستهلك من مصادر ها بالقدر الذي يحقق البيئة الصحية لمستخدميها ولا يخل بحق الأجيال المستقبلية في تلبية احتياجاتهم من المصادر الطبيعية. فالتصميم المستدام للمو اقع هو عملية يتم بموجبها مر اعاة اعتبارات الجودة البيئية في تصميم وتخطبط و إدارة البيئة وطبقا

للمبادئ التالية:V] 
تنشمل المبادئ التصميمية الجمالية للمو اقع مبادئ البساطة والتنوع و الإتزان و التأكيد و التتابع ومر اعاة المقياس والإضـاءة و الظل و التى من خلالها يتم التأكد من كون التصميم جذاباً ومتو افقاً مع المحيط من الناحية البصرية و أنه يتعامل بحساسية

وتو افق مع البيئة المحيطة.

المبادئ التصميمية الوظيفية:

يقاس المنتج التصميمى بمدى استيفاؤه للمتطلبات الوظيفية من خلال عنصرين:

تحقيق المعايير الكمية للمحتوى الفر اغى وهو مايعبر عنه بالمعدلات التصميمية والتخطيطية.

تحقيق أفضل علاقات بين العناصر المكونة للحيز الفر اغى.

كما أن الوظيفة ينبغى أن تكون ملائمة تماما للحيز الحاوى لها، بمعنى أن يحقق النتاج التصميمى المستدام التوافق و الانسجام والاتزان و المرونة والإيجابية مع الوظيفة المطلوب استحداثها داخل النطاق، وذللك من خلال الوعى بماهية الاعتبار الوظيفى وبما يحقق رضا المستعمل، والدراية بالوسائل التى تمكن من تحليل طبيعة النسق السلوكى أو الوظيفى

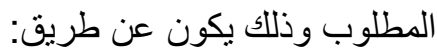
تحديد معدلات الإستخدام والمسطحات المطلوبة.

در اسة الأنماط السلوكية وهو يأتى بالملاحظة المباشرة أو غير المباشرة أو بالاستبيان. ويجب طبقا لهذه المبادئ أن يكون التصميم مستخدماً، ويحقق معايير الصحة والأمان، و ويقابل إحتياجات السكان

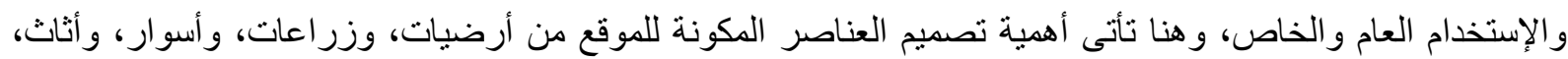
وحو ائط، وممر ات ومشايات تربط المو اقع بالأماكن المختلفة المحيطة بها، وكذلك تصميم الملاعب و الثوارع. كما تظهر أهمية التعامل مع طبو غر افيا الموقع بحيث ير اعى توفير الميول المناسبة للإستخدام، والعروض الملائمة لحجم الحركة عليها، و علاقة مو اضع الممر ات بالنواحى البصرية للحديقة. كما نظهر أهمية أماكن التجمعات داخل المو اقع وما بها من أثاث كأماكن الجلوس، والبرجولات والته والتى تتنأعلى إمتداد الممرات والمشايات فى الموقع حيث تعمل على تغطية وتظليل هذه الممرات وتوفير فرصة التجمع وممارسة الأنشطة الإجتماعية و الترفيهية.

\section{المبادئ التصميمية البيئية:} تركز المبادئ التصميمية البيئية للمو اقع على النقاط الآتية-: أ- تحسين البيئة من خلال تنسيق المواقع: بتنسيق المو اقع بالعناصر الطبيعية من غطاء نباتى ومسطحات مائية وتربة طبيعية مكثوفة يتحقق نوع من الإتزان البيئى و الايكولوجى داخل المحتوى العمر انى، كما يمكن النظر إلى هذا الهدف ياعتبار البعد الإستدامى لتنسيق هذه المو اقع[^]. ب- تعزيز ورفع قيمة المناخ المحلى: من خلال السماح بعبور الرياح أو العمل على حجز هاخ فى حالة عدم الرغبة فيها ، وتوفير الإظلال للمنشآت و المواقع الخارجية والحماية من شمس الصيف، مع السماح بالتعرض للشمس شتاءً، و العمل على التحكم فى الرطوبة من خلال التحكم فى حركة الرياح، والإستفادة بالخصائص الطبو غر افية للموقع وتوظيفها فى توفير المناخ المحلى المناسب.

ت- تحسين البيئة المناخية: من خلال:

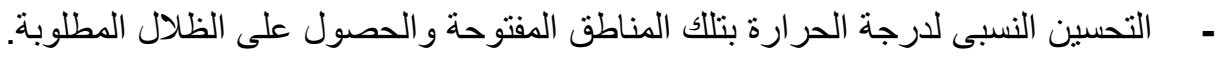
- التعامل مع الرياح ونشاطها و التحكم فى اتجاهها. 


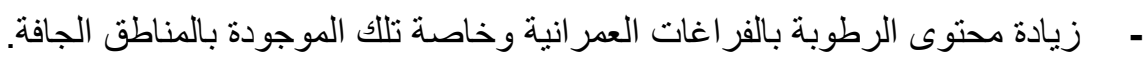
- تحسين جودة الهواء: حيث يمكن لشجرة واحدة أن تزيل جب باوند من ثانى أكسيد الكربون من الغلاف الجوى سنويا،

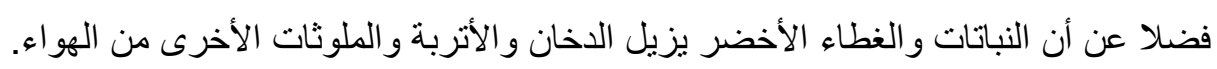
- تخفيض درجة الحر ارة بالصيف: وذلك من خلال التظليل.

ثـ- ترشيد الطاقة من خلال تنسيق المواقع: يساعد التنسيق الجيد للمواقع فى ضبط الطنافي المناخ المصغر وبالتالى توفير بيئة حرارية مريحة وترشيد كبير فى استهلاك

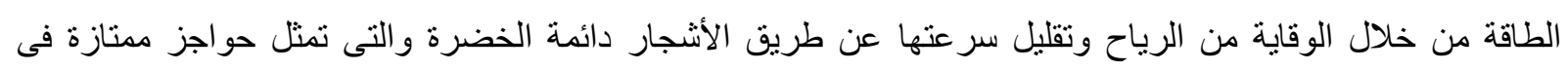

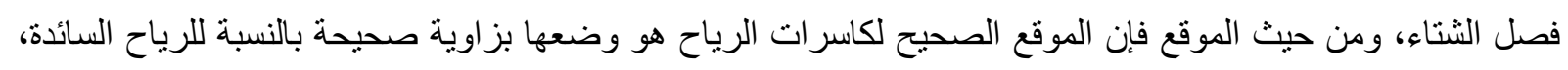

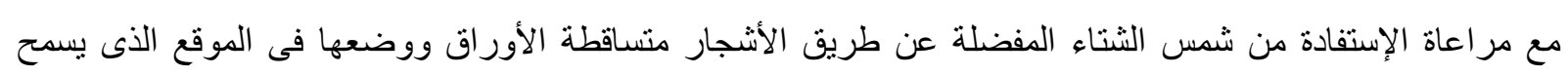

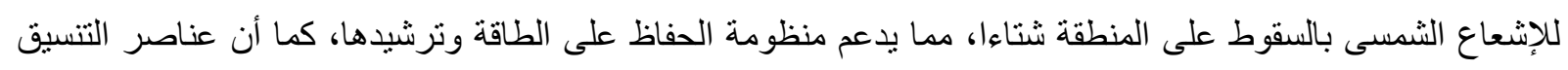
النباتية تساعد فى خفض درجة الحر ارة وزيادة نسبة الرطوبة. بلئ.

ج- ترشيد المياة من خلال تنسيق المواقع: وذللك عن طريق التعامل مع الطبيعة ومع العو امل الطبيق الطبيعية كمياه الأمطار لخلق تنسيق موقع حيوى ومقبول جماليا وفى نفس الوقت استخدام كمية مياة قليلة فى التنسيق، ويستدعى ترشيد استهلاك المياه فى التنسيق الملاحظة المتأنية والتخطيط و التصميم الجيد والإنتقائية لنو عية النباتات المستخدمة والأدوات الجيدة المرشدة.

\section{المبادئ التصميمية الإجتماعية:}

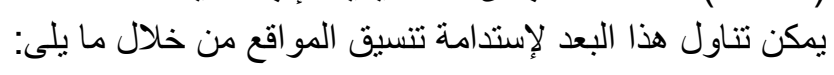

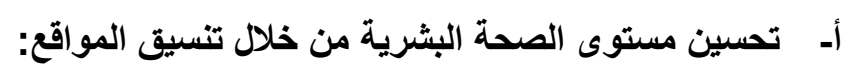
الثفاء من خلال تنسيق المواقع: حيث تساعد الحدائق كبيئة محيطة فى استعادة النقة للمرضى وفى شفاء العديد من الأمراض، حتى ان المرضى بالمستشفيات و الذين لهم غرف مطلة على المسطحات الخضراء و المنسقة بشكل جيد يتم

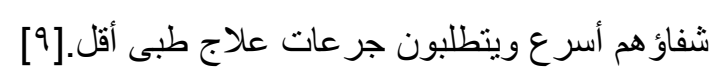
الدور المعنوى والجمالى: حيث يساعد تتسيق المو اقع فى الراحة النفسية وفرصة الإختلاء بالنفس وإعادة الإتزان النفسى من خلال الإمداد بالمتعة البصرية وديناميكية عناصر تنسيق المواقع فضلا عن المردود الجمالى فى تحديد وربط أجزاء التهاء

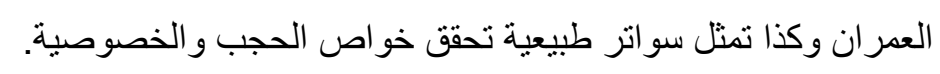

ب- الإمداد بالخصوصية من خلال تنسيق المواقع:

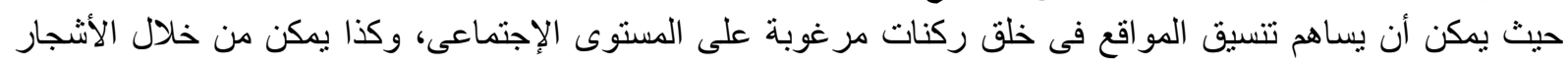
و المدادات و الخمائل معالجة الفتحات المعمارية محققا بذلك بعدين: أحدهما الخصوصية، ولكئ والآخربعد جمالى.

تـ- الإمداد بمظهر وخلفية جمالية تزيد من الإقبال على المنطقة:

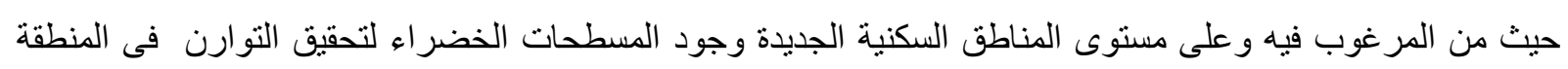

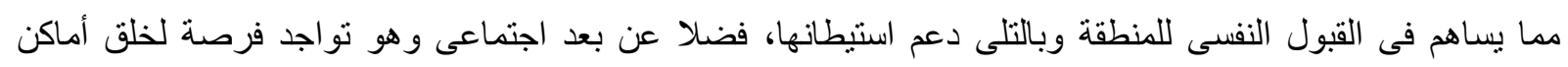


احتكالك ولقاء وتقارب مجتمعى مما يساعد على تقوية المشاركة ونمو السلوك الإيجابى لدى الأفراد تجاه تحسين البيئة

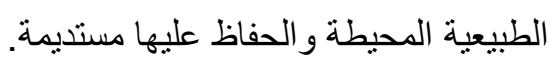

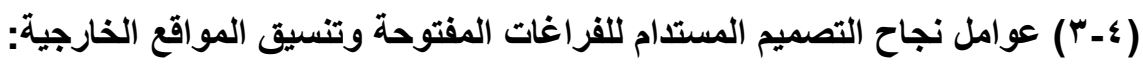
إن نجاح تصميم الفر اغات المفتوحة، وتحقيقها للأهداف المرجوة منها يشكل نتيجة كلية للمعالجات الذئية الكية للعو امل المؤثرة فى الموقع المراد إقامة المناطق الخضراء به، وتختلف هذه العوامل من موقع لآخر، إلا أنها تتدرج فى أغلب الأحوال ضمن مجموعة عوامل أساسية، وهى: دراسة خصائص الموقع، التعرف الدقيق على الأهداف والإستعمال، مقابلة

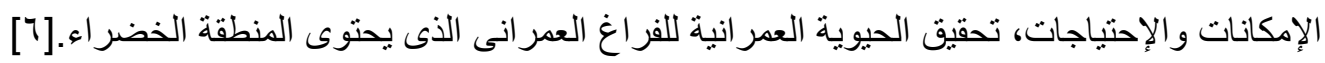

1- دراسة خصائص الموقع:

إن الإلمام الجيد بالخصائص التفصيلية للموقع، وظروفه الراهنة تعتبر مقدمة مهمة لنجاح ما يتبعها من خطوات، حيث أن

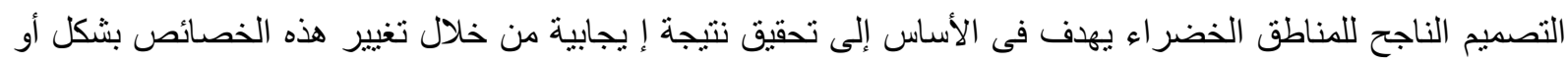
بآخر، وذلك بالتحليل للإجراءات الممكنة لتنسيق الموقع بحسب ملاءمنها لخصائصه، لترشيح قائمة من الأعمال والإجر اءات التى تلائم موقعاً بعينه. و هذه الملاءمة لخصائص الموقع تعنى بالدرجة الأولى جودة التصميم، والتناسق البصرى، والعمر الإفتراضى الطويل

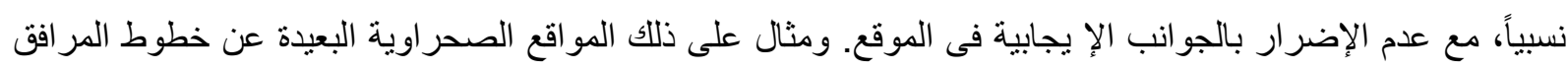
العامة، والخالية من إجراءات الحماية والصيانة الدورية، لذلك يناسبها إستخدام الأشجار المعمرة التى لا لإنى تحتاج إلى مياه بكثرة، والتكونات الصخرية والجلسات المظلله من الأسمنت والأحجار، و لا بلائمها بالطبع إستخدام الحشائش و التكوينات المائية والجلسات من القماش أو الأخشاب.

2- 2 - التعرف الدقيق على الأهداف والإستعمال:

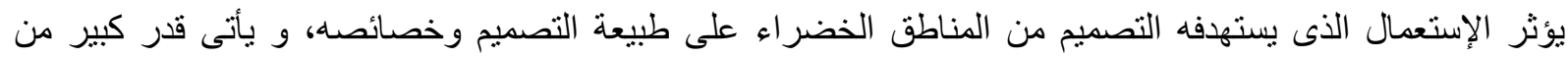
الفشل الذى يحققه تتسيق بعض المواقع من عدم كفاية الإجراءات اللازمة لتيسير هذا الإستعمال والإستخدام، و غالباً ما يؤدى عدم ملاءمة التصميم للمنطقة الخضر اء للإستخدام المخصصة له إلى تلف عناصر التصميم، وتدهور الموقع بشكل عام. ومثال على ذلك عند إستخدام المناطق الخضر اء كملاعب للأطفال مثنلا، فيكون من الملائم إستخدام أرضيات رملية توضع

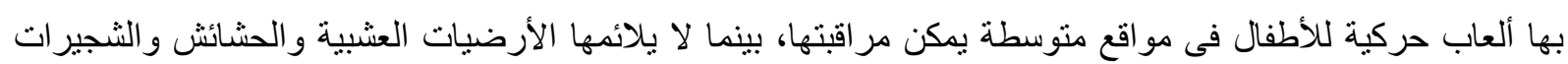
الكثيفة و التكو ينات المائية.

أما ممر ات المشاه فى المناطق الخضر اء التى تستخدم فى الحركة والتنقل بين المو اقع فيلائمها الرصف بالأحجار المنبسطة الملائمة لكل الأحذية، و العربات، بينما لا يلائمها التكوينات الصخرية و الأعثاب الطويلة والثجير ات و النو افير الكبيرة.

3- مقابلة الإمكانات والإحتياجات: تظل القدرات والإمكانات محدداً أساسياً لتنسيق الفراغات المفتوحة، حيث لا يقتصر الأمر على منطلبات الإنشاء و التأسيس، بل يرتبط أيضاً بمتطلبات التشغيل والصيانة، وهى عو امل نتأثر بشكل بالغ بطبيعة الإستخدام، وطبيعة الموقع،

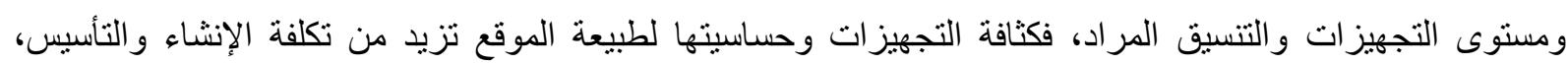
وكذلك التشغيل و الصيانة. 


\section{4- تحقيق الحيوية العمرانية للفراغ العمرانى:}

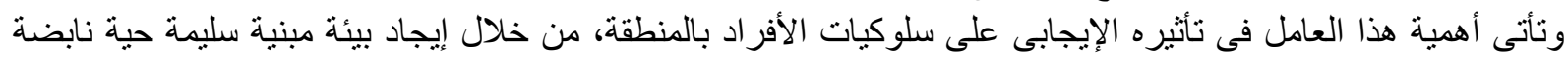
بالحياة، يتفاعل فيها الناس مع البيئة المحيطة بما يولا لديهم الحافز نحو الحفاظ عليها والرغبة فى تطويرها وتحسينها

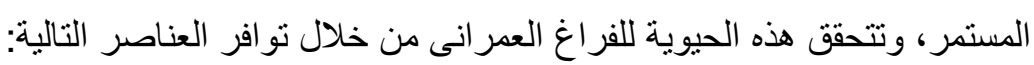
زيادة إمكانية النفاذ والوصول: بما يعمل على توفير فرص الإختراق والتجول داخلها وبما بمكن الأفراد من الحركة و المشاهدة ومزاولة الأنشطة المختلفة. تنوع الإستعمالات: ويكون بزيادة ما يوفره الفراغ العمرانى من تتوع فى الإستعمالات للمبانى المحيطة، وتتوع توعان أشنكالها المادية و المعانى التى تنقلها للمستخدمين. وضوح الصورة البصرية: وذلك بجعل الفراغ أكثر وضوحاً من الناحية البصرية بما يمكن المستخدم من قراءته

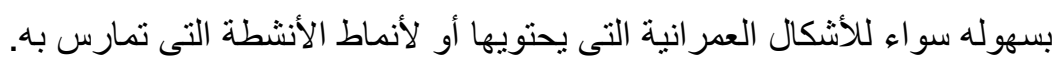
تعدد الأغراض والأنثطة بالموقع: و يكون ذللك بخلق مبانى نشطة فى الموقع تتعدد فيها الأنشطة بحيث تجعل الفراغ

أكثر تنشويقا. الملاءمة البصرية: وتكون بأن يدعم تصميم الفراغ العمرانى المعانى التى تلازمه و التى بفسر الناس بها المكان من خلال دعم الأشكال و الإستعمالات للمبانى وتنو عها. الغنى العمرانى: وذللك بدعم التصميم العمر انى للخبرات الحسية التى يستمتع بها المستخدمين للمواقع والتى تشمل الحس الحركى، وحس الثم، وحس السمع، وحس اللمس، والحس البصرى والذى يتأكد وجوده بالتنوع فى المواد

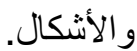
إضافة شخصية السكان على الفراغ العمرانى: وذلك بتمكين سكان المنطقة من وضع بصماتهم و أذو اقهم وقيمهم على الفر اغ العمر انى بما يساهم فى تحسين صورتها وملاعمته لإحتياجاتهم.

(ع ــ) إعتبارات التصميم المستدام للفراغات المفتوحة وتنسيق المواقع الاثرية:

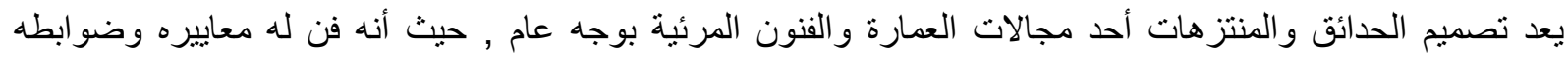

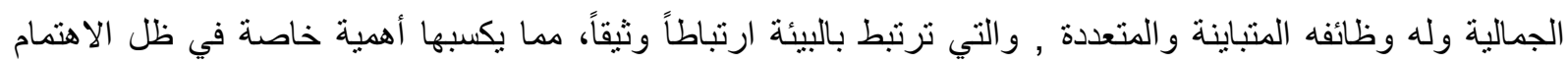

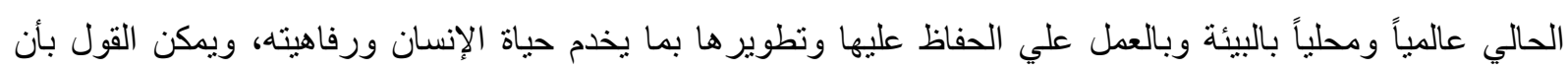
هناك عدة إعتبار ات يجب مر اعاتها عند التصميم المستدام للحدائق العامة و المتنز هات و هى: · ل 1] 1- ت تناسب المساحات المخصصة للحدائق مع كثافة السكان الذين تخدمه هذه المر افق مع مر اعاة التوسع العمر انى.

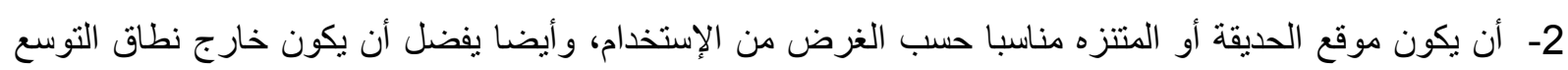
العمر انى فى المستقبل، ليبقى مكانها بعيدا عن حركة السيار ات. 3- مر اعاة الإستفادة من طبو غر افية الأرض، من شعاب وأودية وتلال و غير ها، وذلك بإقامة مناطق ترفيهية ومتنز هات و المحافظة على طبو غر افية المواقع الطبيعية، وتتسيقها كعنصر بيئى للمنطقة. 4- - تحديد الثوارع المحيطة بالحديقة أو المتنزه، وكذلك الثوارع المؤدية إلى المداخل الرئيسية لها، مع مراعاة توفر مو اقف للسيار ات قريبة منها. 5- عزل الحديقة العامة عن الشوارع المحيطة بها بأسوار مرتفعة أو أسيجة كثيفة من الأشجار ومصدات الرياح وذلك

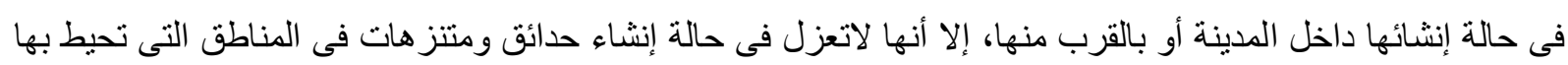


6- مر اعاة توفير جميع العناصر الترفيهية فى الحدائق والمتنزهات بشكل يحقق الإكتفاء الترويحى للسكان و التى تثمل:

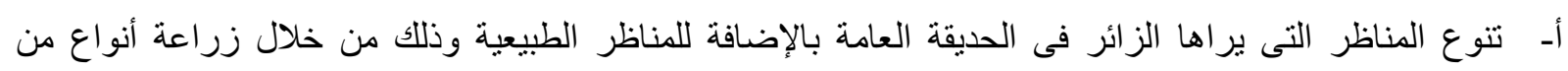

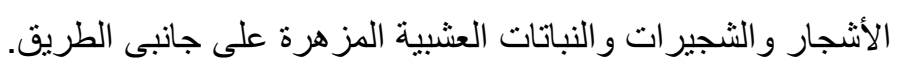

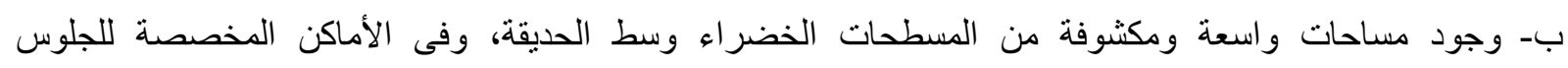

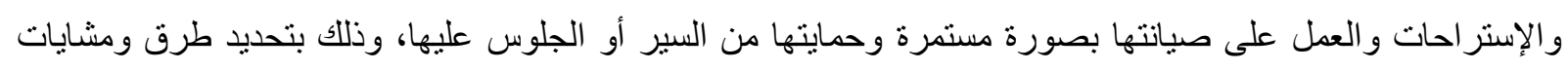
و أماكن للجلوس لز ائرى الحدائق. ت- ملاعب أطفال تحت سن العشر سنوات، وملاعب رياضية للكبار. ثـ أماكن خاصة للجلوس والإستراحات مجهزة بالخدمات المساندة والمرافق الضرورية مثل: المقاعد، أماكن للشواء أماكن بيع المأكو لات و المشروبات، مياه للشرب، دورات مياه، مسجد للصناة. 7- وجود بعض عناصر التنسيق التى تجذب النظر إليها فى تنسيق الحدائق والمتنزهات مثل: وجود الجسور المعلقة أو دأ

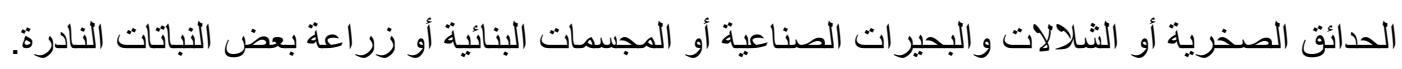
8- وجود نوع من الترابط بين أجزاء و أقسام الحديقة المتباعدة عن بعضها لإظهار ها بصورة منفصلة تربطها ببعضها عناصر التنسيق المستخدمة فى الحديقة.

\section{(0) نماذج تظوير الفراغات المفتوحة للمواقع الأثرية المصرية:} تعد السياحة في مصر أحد أهم مصادر الدخل القومي بما توفره من عائد من العملة الأجنبية التي مكنتها من المشاركة

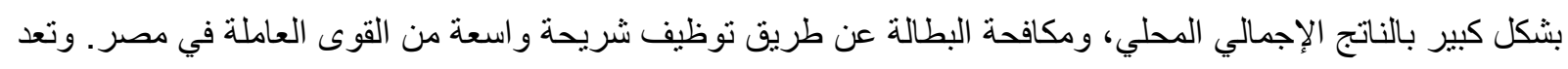

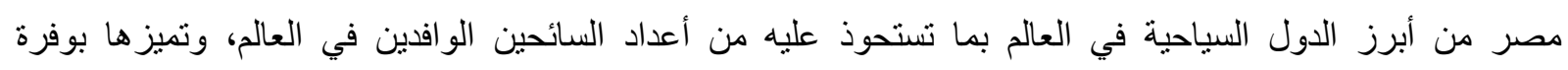

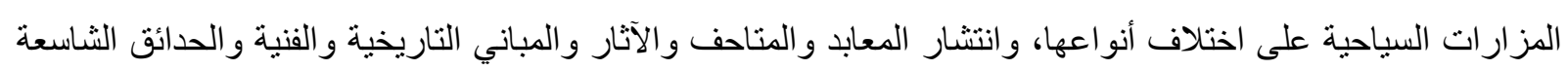

على أرضها. فطالما كانت السياحة ركيزة أساسية في الاقتصاد المصري، إذ تسهم بنحو ب, 1/\% من الناتج المحلي الإجمالي وتوفر

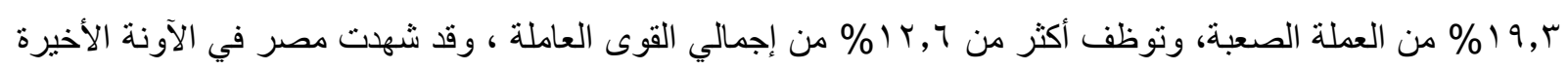
العديد من أعمال التطوير في البنية التحتية، ولم يقتصر التطوير على البنية التحتية فقط بل شمل المناطق التاريخية

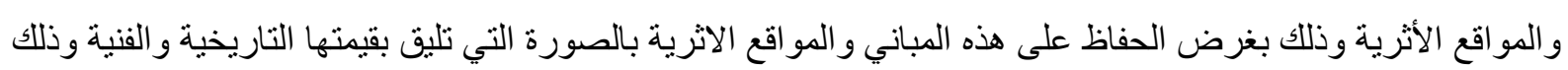
عن طريق أهداف فرعية تتمثل في: 1. توفير عائد مناسب يغطي تكاليف صيانة هذه المباني و إيجاد قاعدة إقتصادية للنطاق. 2. إعادة تكامل الأثر مع محبطه الحالي بتوظيفه فيما يخدم إحتياجات المجتمع المحيط. 3. إيجاد نوع من التعاطف بين المبنى الأثري و المتعاملين معه. 4. تزويد النطاقات النر اثثة بالأحياء القديمة المتدهورة بالخدمات اللازمة لها لهادئ دون الحاجة إلى إقامة مباني جديدة. 5. إستغلال الآثار كنقط جذب سياحية و إستثمار ها لتتمية المحيط العمر اني. 6. إيجاد إثر اف دائم على هذه الأبنية عن طريق المستخدمين و المنتفعين. 7. المع وتدعيم القيمة الإجمالية للمبنى. 8. المشاركة في تتمية المجتمع المحيط بما يدعم الحفاظ على الطابع العمر اني التراثي للنطاق. 
(1- (1) مشروع تطوير منطقة عين الصيرة - مصر القديمة بالقاهرة التاريخية:

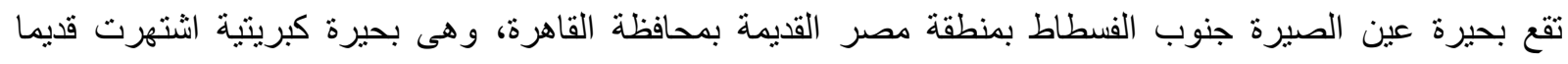

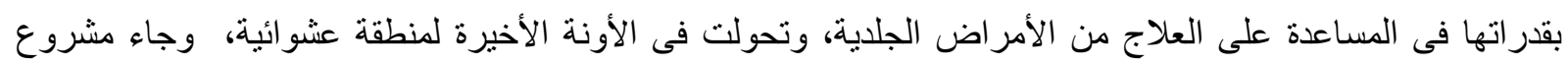

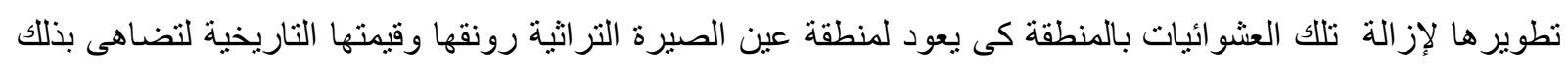
الوجهات السياحية العالمية.

ويتم تنفيذ مشروع تطوير بحيرة عين الصيرة على مساحة با فدانا، حيث يشمل تتفيذ ممشى سياحى حول البحيرة بطول . . . . م طولي، ومنطقة مطاعم، وجزيرة استو ائية وسط البحيرة، ومسرح مكثوف، ومناطق خضر اء، ومظلات خشبية، وخمس مجمو عات نو افير عائمة داخل البحيرة، ومحطة معالجة لمياه البحيرة. المخطط يعمل على إنشاء أنشطة واستخدامات بديلة تؤكد وظيفة القاهرة كمركز ثقافى حضارى سياحى، مع عماية الهية الهوية التاريخية من خلال التكامل مع النسيج العمر انى التاريخى للمنطقة، وتحقيق التزاه اوج و التكامل بين البيئة التاريخية المتميزة للموقع والبيئة العمر انية التي سيتضمنها الموقع الجديد، وخلق بيئة عمر انية ملهمة وتتطوى على الخيال و الرؤية لمقصد سياحى ذى شخصية متميزة وتقديم تجربة عمر انية وسياحية متميزة وقابلة للمنافسة.

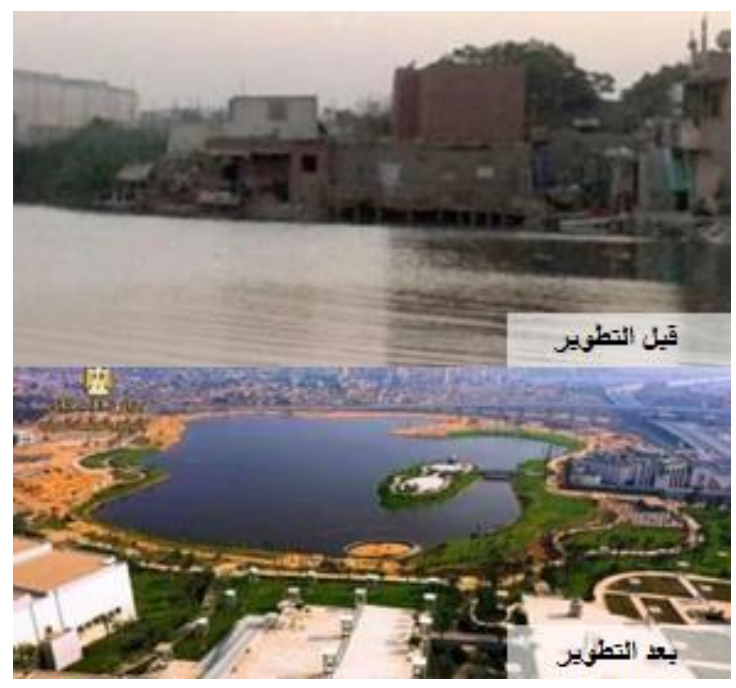

صورة ( ) توضح التطور الذي طرأ على منطقة عين الصيرة بعد إزالة العشوائيات لتستعيد المنطقة قيمتها التاريخية
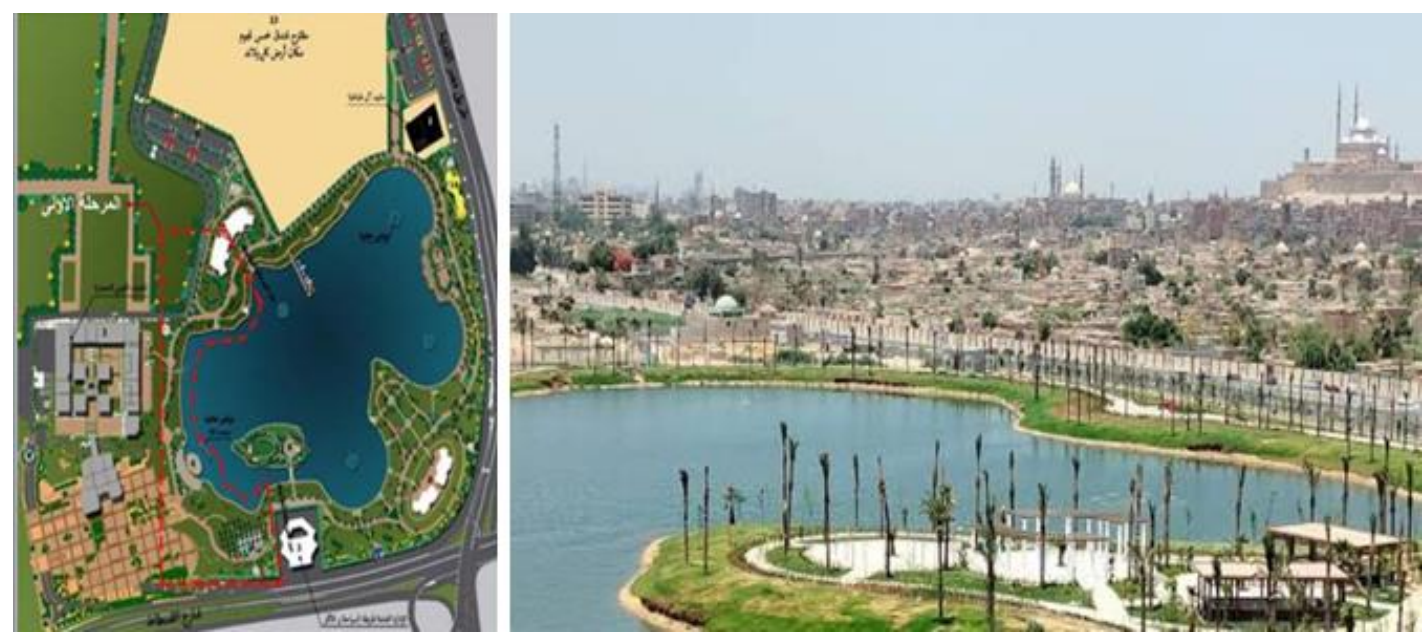

صورة (0) مسقط أفقي لمخطط التصميم ولقطة منظورية للمنطقة بعد تطويرها

ليعكس تنسيق الموقع القيمة الحضارية و التاريخية للمكان و الارتقاء به واستثماره 


\section{الاعتبارات التصميمية المستدامة لتنسيق الموقع عين الصيرة:}

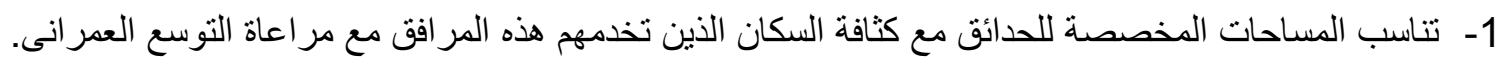

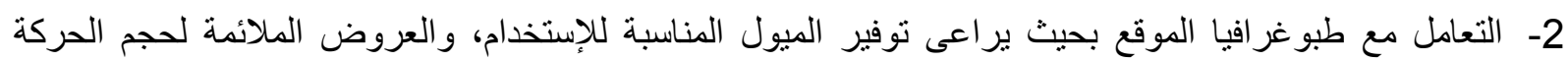
عليها، و علاقة مو اضع الممر ات بالنو احى البصرية للحديقة. 3- عزل الحديقة عن الثوارع المحيطة بها بأسوار مرتفعة أو أسيجة كثيفة من الأشجار ومصدات الرياح وذللك فى حالة

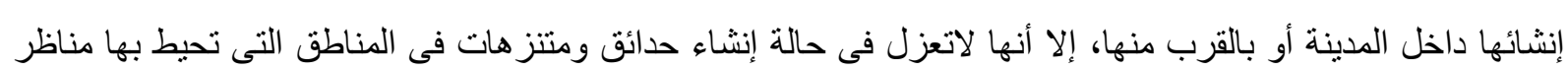
طبيعية. 4- تتوع المناظر التى يراها الزائر فى الحديقة بالإضافة للمناظر الطبيعية وذلك من خلال زراعة أنواع من الأشجار و الثجيرات والنباتات العشبية المزهرة ، و إضافة العنصر المائي ، وتوفير أماكن خاصة للجلوس و المظلات و الإستر احات المجزةة بالخدمات المساندة والمر افق الضرورية. 5- حرص التصميم على إيجاد بيئة مبنية سليمة حية نابضة بالحياة، يتفاعل فيها الناس مع البيئة المحيطة بما يولد لايهم الحافز نحو الحفاظ عليها والرغبة فى تطوير ها وتحسينها المستمر، وتتحقق هذه الحيوية للفر اغ العمر انى. 6- حرص التصميم على دراسة خصائص الموقع، التعرف الدقيق على الأهداف والإستعمال، مقابلة الإمكانات

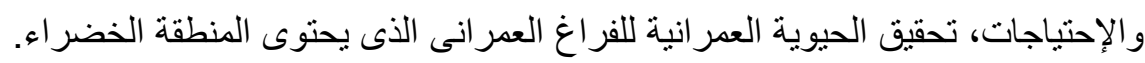
7- التصميم يثير البهجة من الناحية البصرية والتكامل مع باقى الأهداف الأخرى دون التأثير سلبياً على القيمة الجمالية للتصميم.

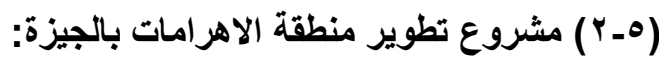
مجمع أهرامات الجيزة هو موقع أثري على منى هضبة الجيزة، على مشارف القاهرة، مصر .ويشمل الأهرامات الثلاثة الكبرى "خوفو، خفرع، منقرع"، وأبو الهول العظيم، وعدة مقابر، وقرية عمالية ومجمع صناعي. يقع في الصحراء

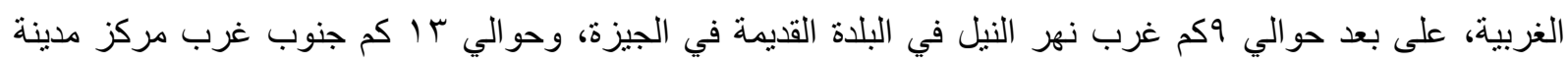

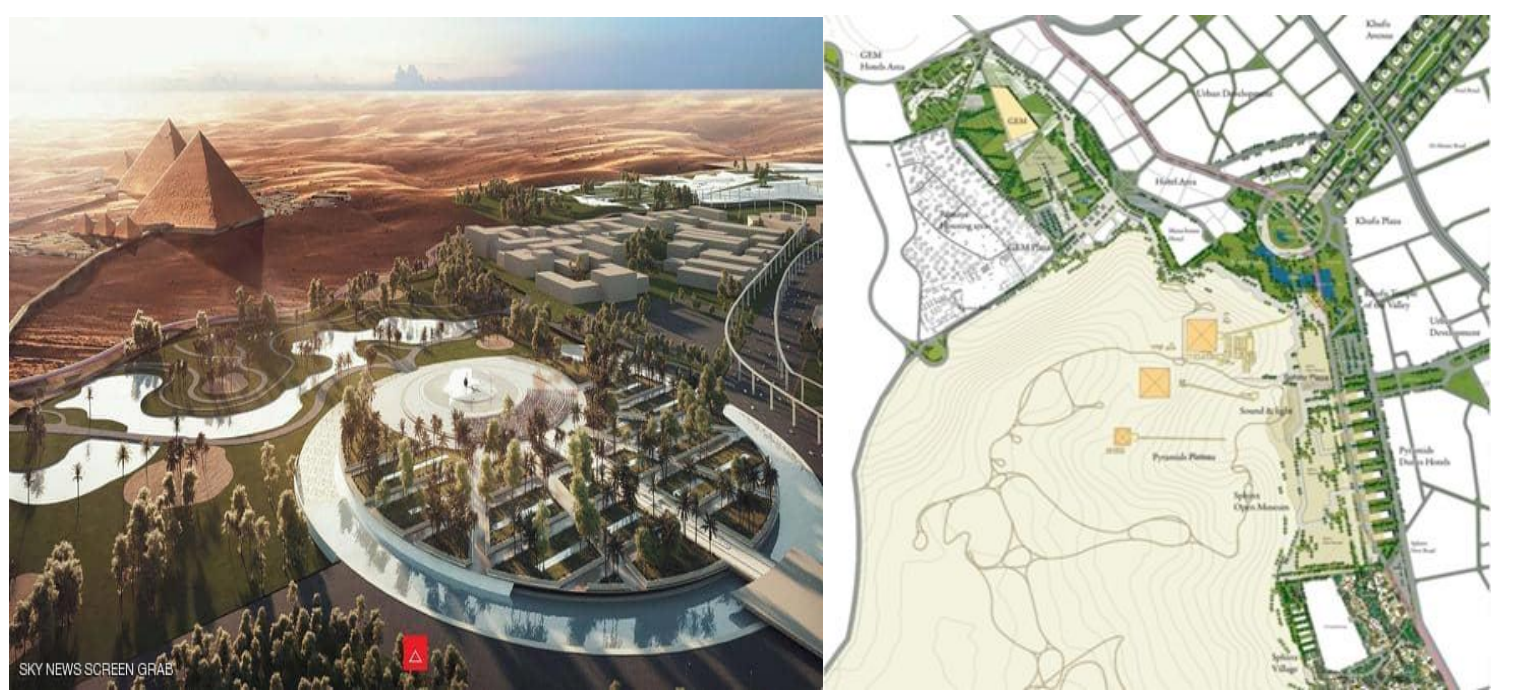

صورة (?) الرسوم التخطيطية و التصميم المقترح من مركز هندة الآثار جامعة القاهرة، في إطار المخطط الابتائي الذي أعدته منظمة اليونسكو وتبناه المجلس الأعلى للآثار 
يهدف المشروع إلى:- استثمار مقومات المكان كعنصر جذب سياحي، وترفيهي عالمى -فتح محور بصري مرورى

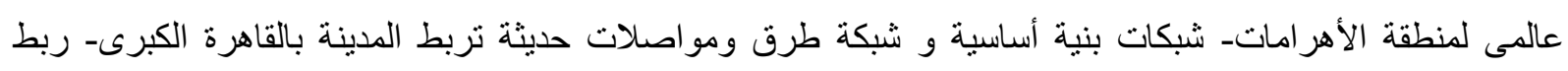
هضبة الأهرام بالمتحف المصرى الكبير ونطوير المنطقة المحيطة الأهر امات لتصبح منحف مفتوح -جودة حياة وعمران به كافة الخدمات المطلوبة فى العصر الحديث لسكان محافظة الجيزة.
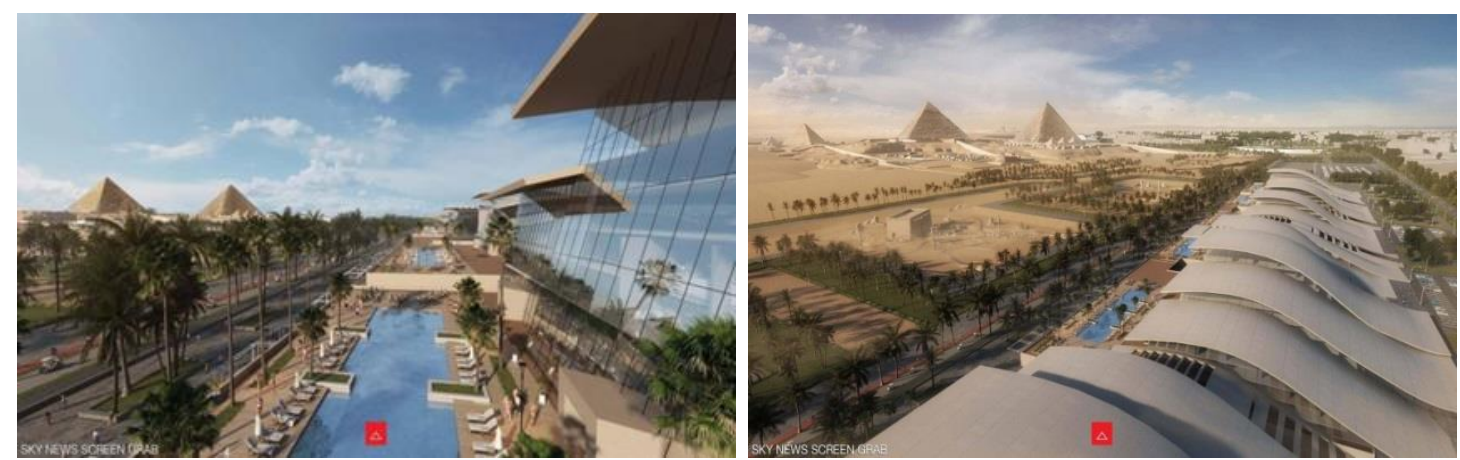

صورة (V) لقطات منظورية تخيلية للتصميم المقترح لتظوير منطقة الاهرامات وربطه بالقيمة التاريخية للاهر امات الثلاثة التي تظهر في خلفية التصميم

كما يهدف مشروع إلى حل مشاكل التداعي العمراني والبصري و التي كان لها الأثر السلبي على قيمة المنطقة الأثرية التاريخية ، وتوفير الخدمات الثقافية والسياحية للزائرين.،و التجهيزات و المسطحات اللازمة للأجهزة الإدارية والأثرية والأمنية أعلى الهضبة. كذلك التحكم في حركة الخيول والجمال والدواب داخل النطاق الأثري والحد من نأثثر اتها السلبية.حماية الهضبة من التعديات و الامتدادات العمر انية العشو ائية.

\section{(7) (المقترح التصميمي التنسيق موقع ساحة معبد الأقصر:}

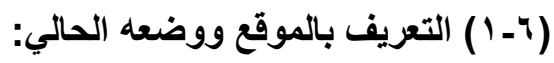

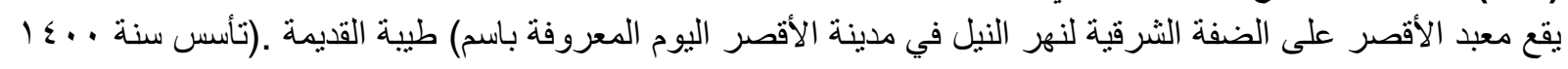

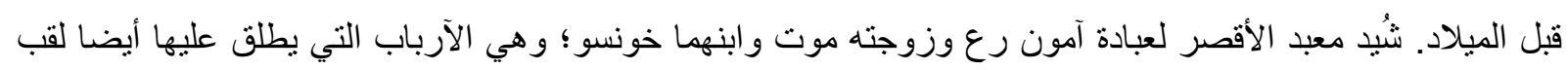

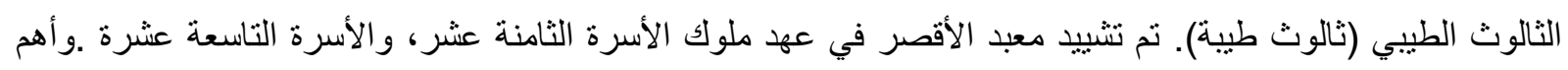

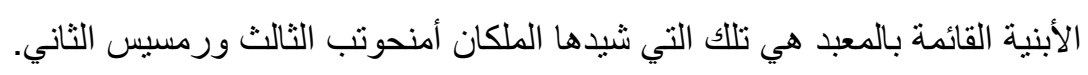
يعد معبد الأقصر، أحد أشهر المعابد في محافظة الأقصر، يوجد في وسط المدينة، يعلوه مسجد سيدي أبو الحجاج

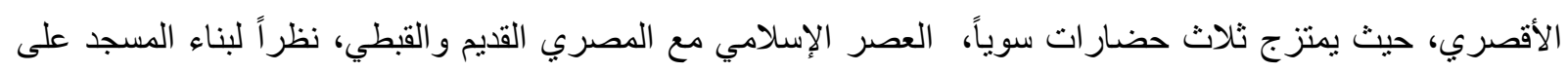

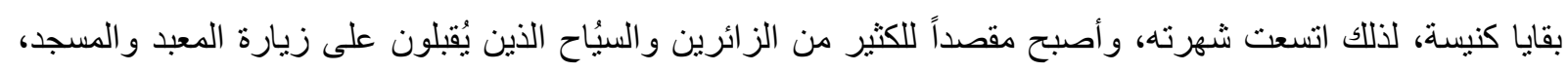
مما كان سبيا في إختيار ساحة المعبد لوضع مقترح تصميي لفراغها الخارجي المفتوح بهدف الارتقاء بالموقع الاثري

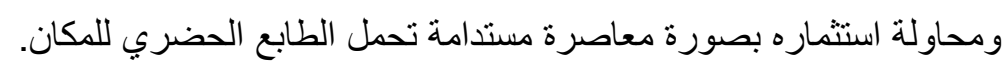


ديسمبر I.Y.Y مجلة التراث والتصميم ـ المجلد الاول ـ العدد السادس
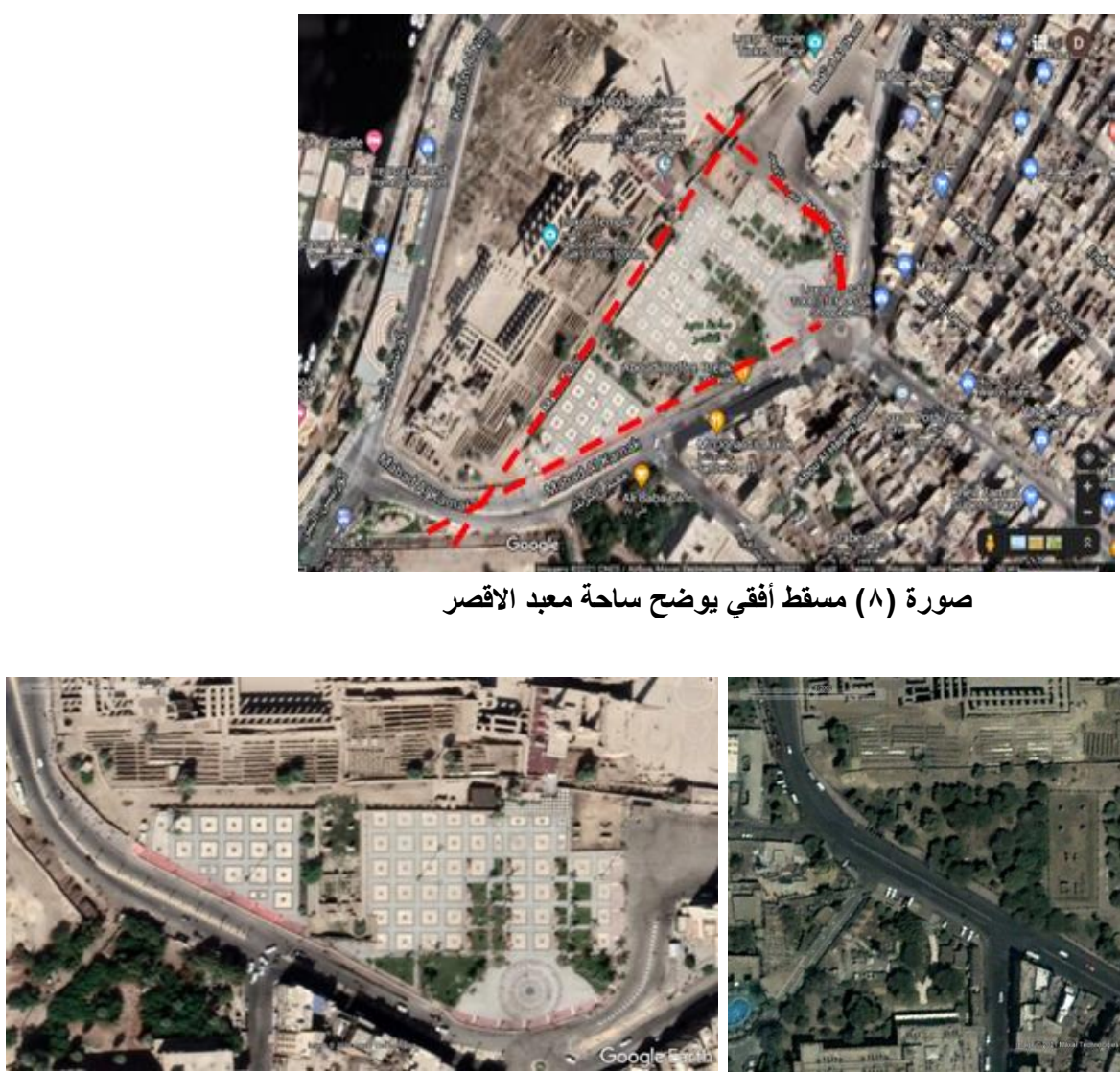

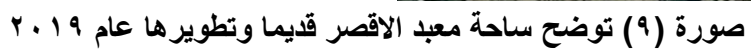

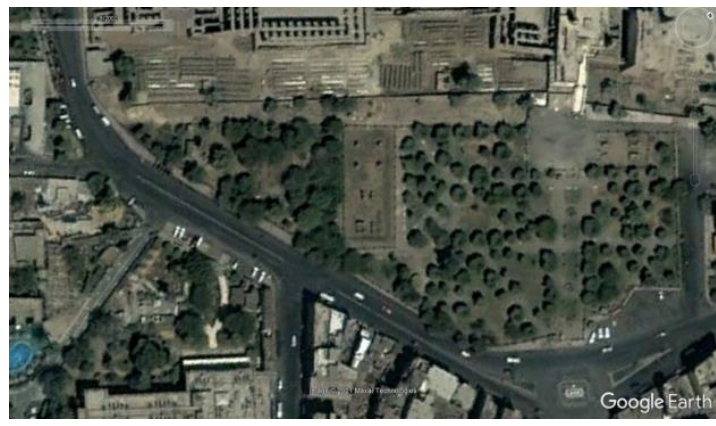

المشاكل التي تواجه الوضع الحالي لساحة معبد الأقصر:

1- سوء الاستخدام واللامبالاة في التعامل مع هذه المواقع والمباني بسبب انخفاض المستوي الثقافي والتعليمي و الحضاري لساكني هذه المناطق. 2- التأثير السلبي علي الصورة البصرية المتكاملة وتغيير شخصية المبني كجزء من العدر ان المحيط. 3- نص مصادر التمويل اللازم لمشروعات تخطيط المواقع الأثرية عمر انيا= ومعمارياً .

4- غياب القو انين و التشريعات اللازمة للحفاظ علي الأبنية الأثرية وخاصة فيما يتعلق بالعمر ان المحيط. 5- عدم وجود الأجهزة الفنية المؤهلة والمدربة القادرة علي تنفيذ أو متابعة تنفيذ مشاريع الحفاظ علي المناطق الأثرية.
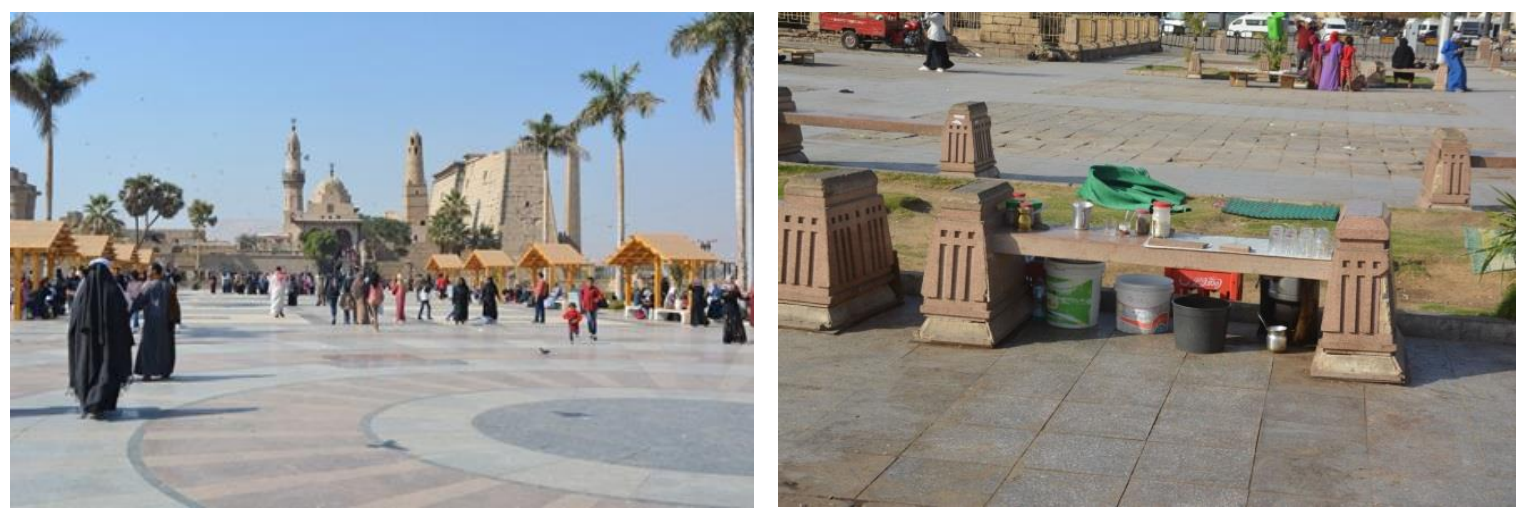

صورة ( • 1) توضح سوء الاستخدام والتعامل مع المنطقة الاثرية، وسوء التصميم لتلبية احتياجات الافراد

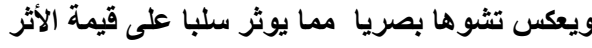


تعد ساحة معبد الأقصر عنصر جذب قوي للسائحين، وذلك لما يحبطها من معالم أثرية تعبر عن حضار ات عدة مثل معبد الأقصر و الذي يعكس الحضارة المصرية القديمة بأصالتها وقوتها، و الكنيسة الني تعبر عن الحضارة القبطية ومسجد أبي حجاج الأقصري الذي بني على انقاض الكنيسة، والذي يرمز للحضارة الإسلامية، لذا جاء التصميم معتمدا على عنصر

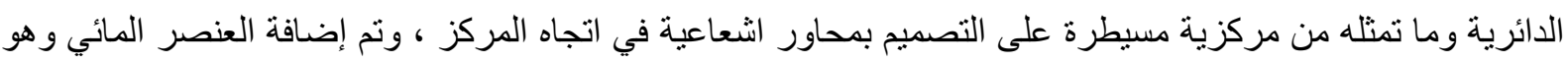

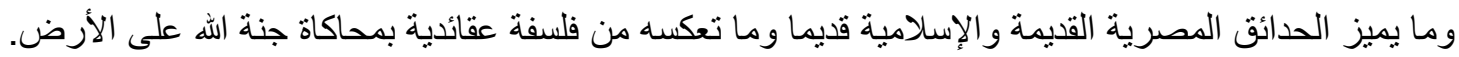
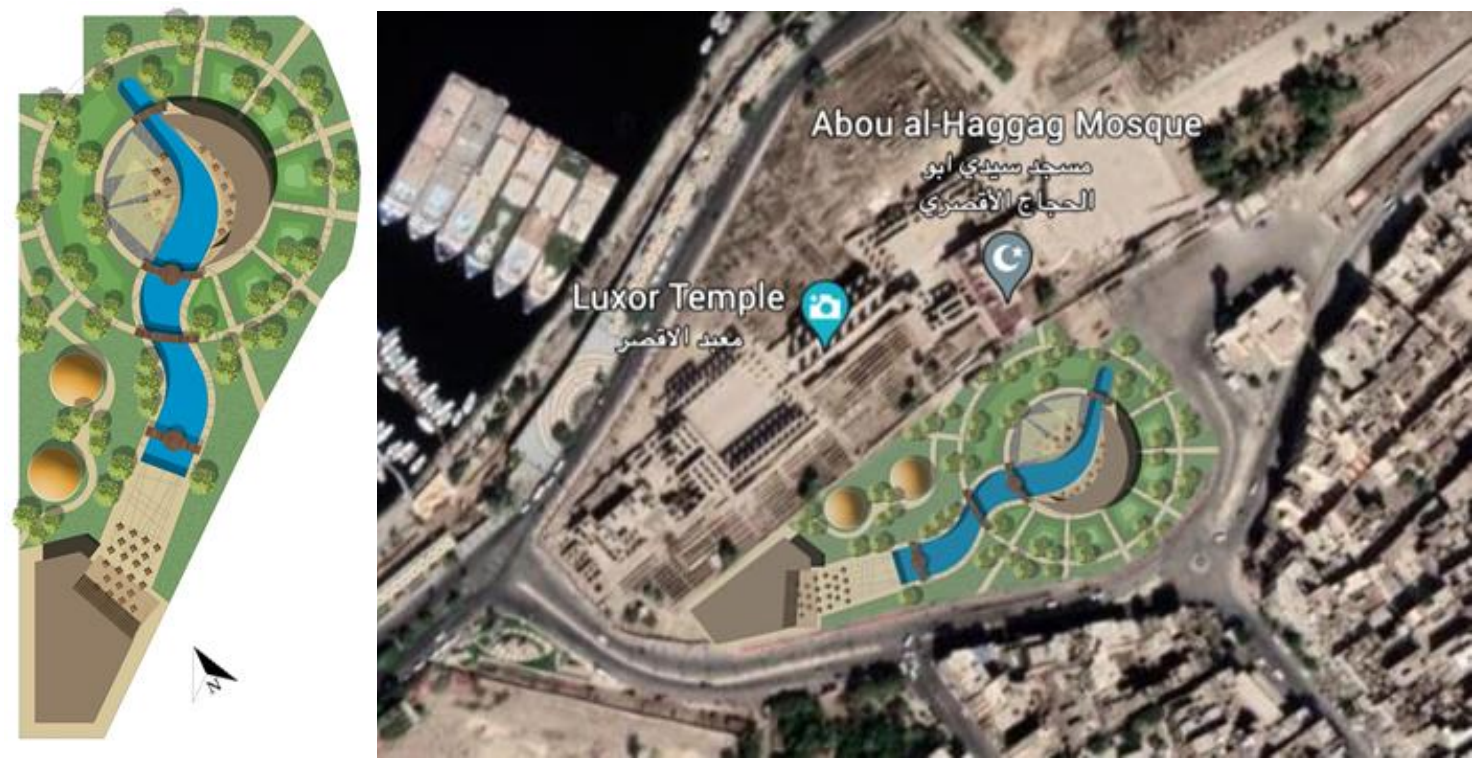

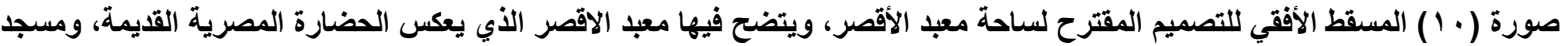

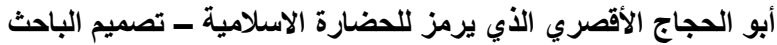

\section{أسس واعتبارات التصميم المقترح لساحة معبد الاقصر:}

سعى التصميم لتحقيق أهداف الدراسة والبحث وتطبيق المبادئ التصميمية الجمالية والوظيفية والبيئية والاقتصادية

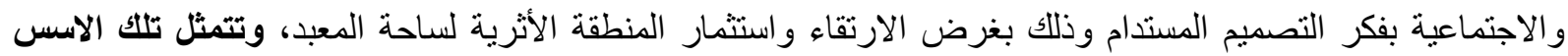

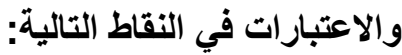

1- توفير فرص الإختراق و التجول داخل الساحة وبما يمكن الأفراد من الحركة والمشاهدة ومزاولة الأنشطة المختلفة من خلال دراسة ممر ات الحركة.

2- مر اعاة توفير جميع العناصر الترفيهية بشكل بحقق الإكتفاء الترويحى للسكان والزائرين، فحرص التصميم على وجود الأمكان المخصصة للعب الاطفال، أماكن الجلوس المظللة، وجود المقاهي على الطرازين الإسلامي والمصري القديم لمحاكاة وجود المعبد و المسجد. 3- تنوع المناظر التى يراها الزائر فى الحديقة العامة بالإضافة للمناظر الطبيعية وذلك من خلال زراعة أنواع من الأشجار و الثجير ات والنباتات العثبية المزهرة على جانبى الممرات، وجود العنصر المائي وما يضبفه للمكان من راحة نفسيه وتأثثير بصري. 
4- وجود مساحات واسعة ومكثوفة من المسطحات الخضراء وسط الساحة، وفى الأماكن المخصصة للجلوس

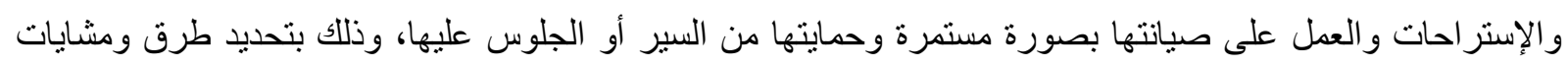
وأماكن للجلوس لز ائرى الساحة.

5- توفير أماكن خاصة للجلوس والإستراحات مجهزة بالخدمات المساندة والمرافق الضرورية مثل: المقاعد، أماكن للشواء أماكن بيع المأكو لات و المشروبات. 6- تحقيق جودة التصميم، والتناسق البصرى، والعمر الإفتراضى الطويل نسبياً، مع عدم الإضرار بالجوانب الإيجابية فى الموقع وقيمتها الحضارية.

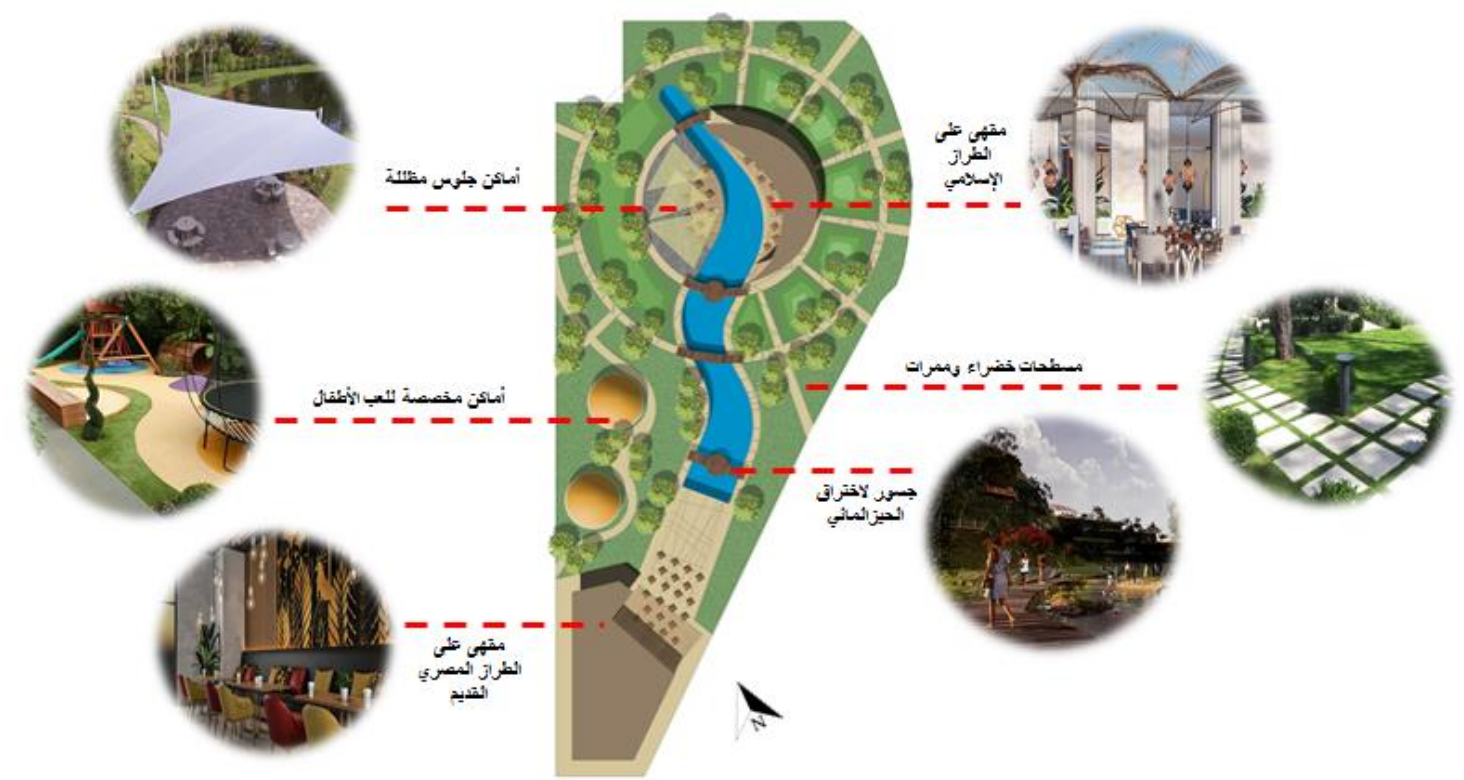

صورة (1 ا ) مسقط أفقي يوضح توزيع الاتشطة المختلفة بالفراغ المفتوح لساحة معبد الأقصر من أماكن الجلوس ولعب الأطفال وممرات

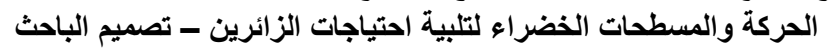

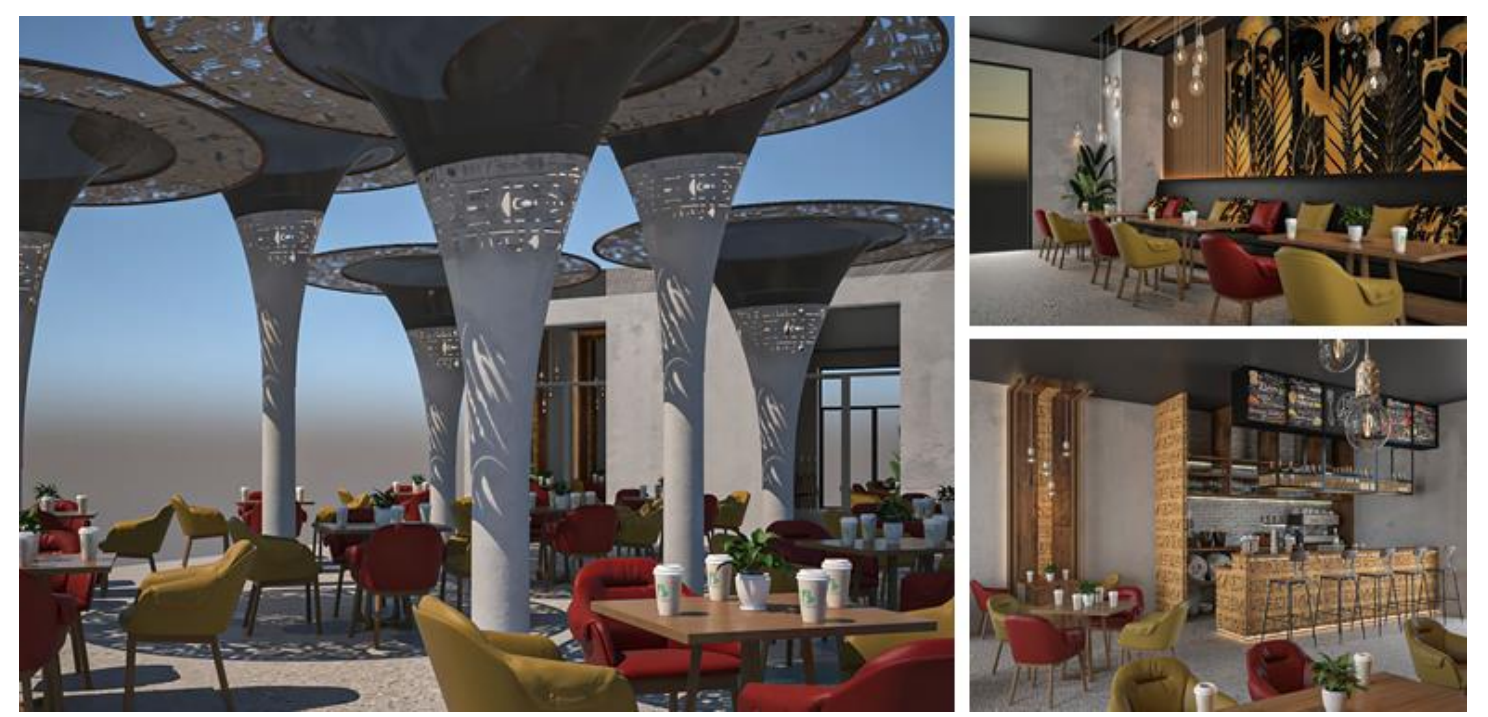

صورة (r ( ) لقطات منظورية داخلية وخارجية لمقهى ساحة معبد الاقصر والمصممة على الطراز المصري القديم لتتكامل الفكرة في حيزها الفراغي مع معبد الاقصر - تصميم الباحث 

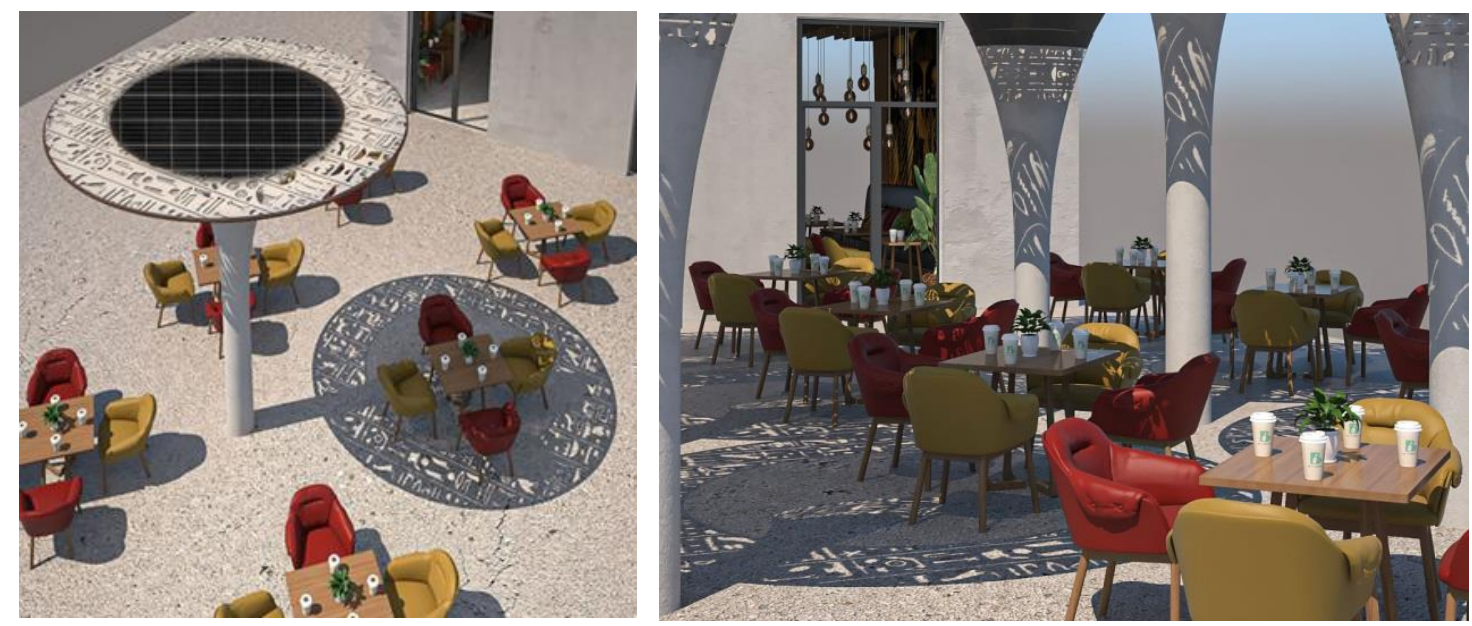

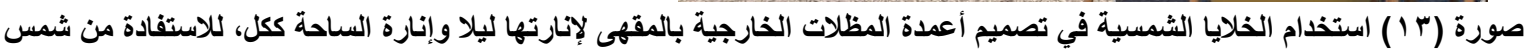

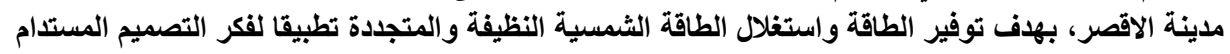

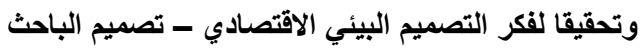
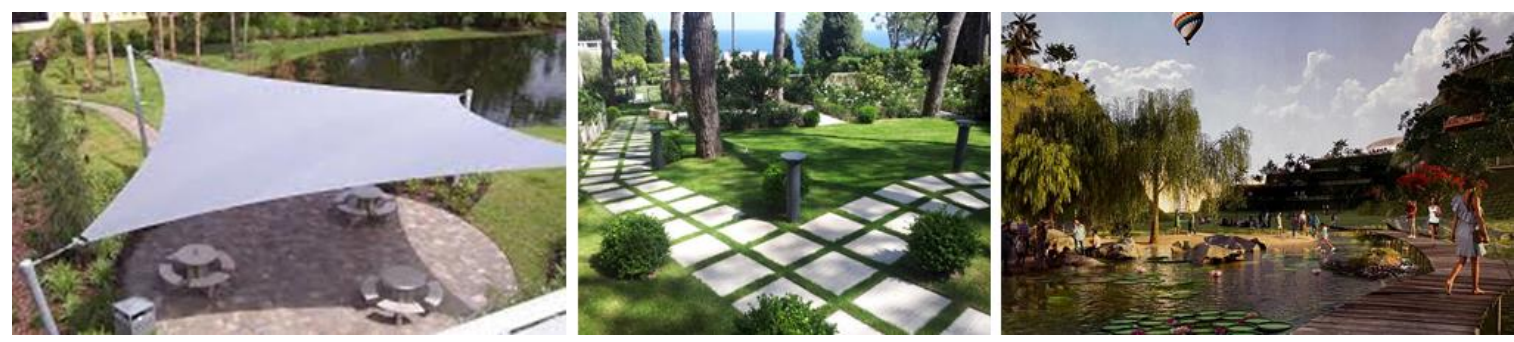

صورة (؛ ا ) مقترحات تصميمية للمساحة المائية وممرات الحركة ومنطقة الجلوس المظللة لساحة معبد الاقصر بما يتماشى مع التصميم

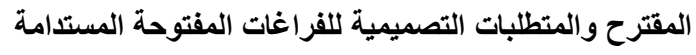
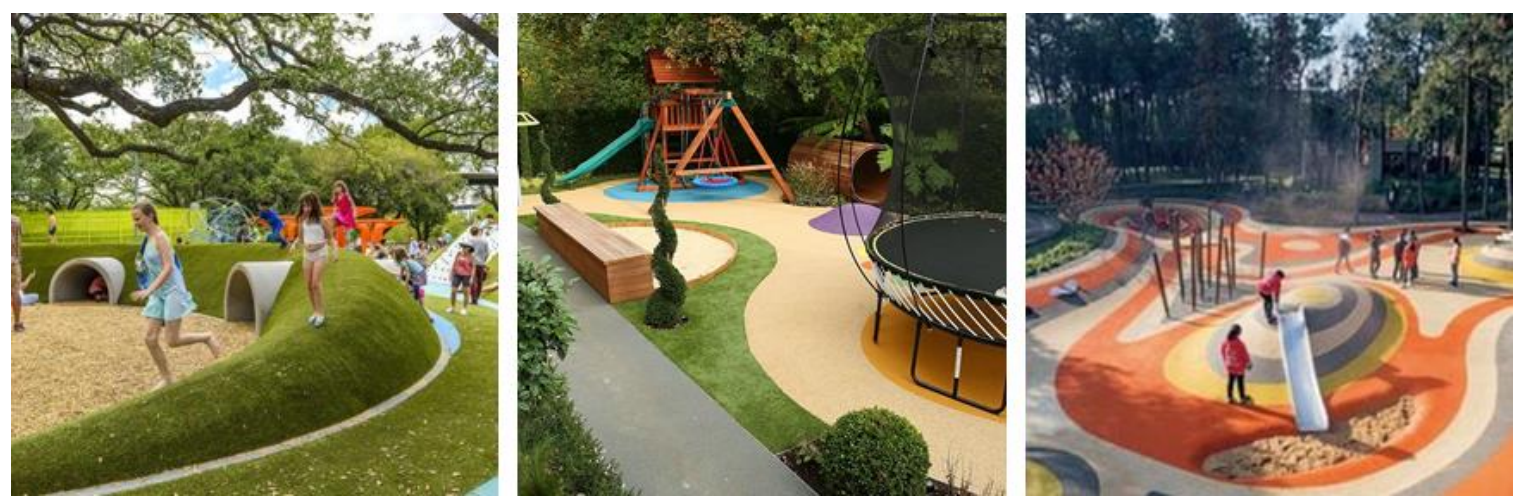

صورة (0 1 ) مقترحات تصميمية لمنطقة الألعاب لتحقيق الإكتفاء الترويحي للأطفال، مع توفير عامل السلامة والأمان بما يتوافق مع المبادئ التصميمية الوظيفية

وبدراسة المقترح التصميمي يتضح أن لتنسيق المواقع الأثرية دورها الأساسي في التنمية والارتقاء بتلك المواقع،

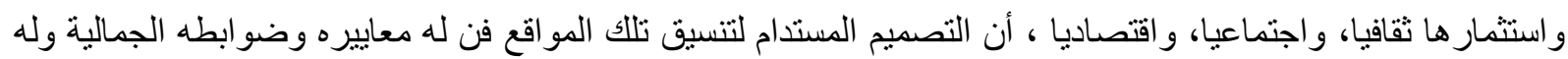
وظائفه المتباينة والمتعددة، و التي ترتبط بالبيئة ارتباطاً وثيقاً، مما يكسبها أهمية خاصة في ظل الاهتمام الهام الحالي عالمياً ومحلياً بالبيئة وبالعمل علي الحفاظ عليها وتطوير ها بما يخدم حياة الإنسان ورفاهيته. 
1- التصميم المستدام لتنسيق المواقع الاثرية يعزز الجودة البيئية ويحافظ على مصادر البيئة الطبيعية، ويلبي منطلبات واحتياجات المجتمع في الوقت الحاضر وفي المستقبل وتحسين نوعية الحياة.

2- تتعرض المواقع الأثرية للعديد من التعديات التي تؤثر سلبا سواء على المستوى المادي أو المستوى البصري أو واو

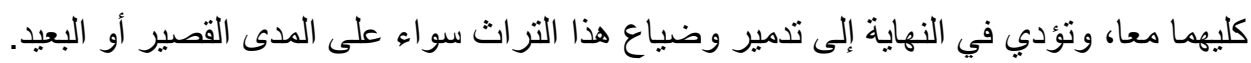
3- يعتد الحفاظ على تتسيق المواقع الاثرية على مدخلين اساسيين هما: الحفاظ للارتقاء بالنطاقات الأثرية، والحفاظ

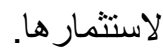
4- إعادة إستخدام المباني التراثية في أغر اض تخدم المجتمع وتوفر الفائدة المباشرة له يؤدى إلى إهتمام المجتمع بمشاريع الحفاظ والإرتقاء. 5- الإلمام الجيد بالخصائص التفصيلية لتنسيق المواقع الاثرية يعد المقدمة لنجاح التخطيط و التصميم وملاءمته لتحقيق الحيوية العمر انية للفر اغ العمراني.

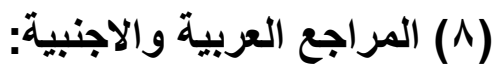

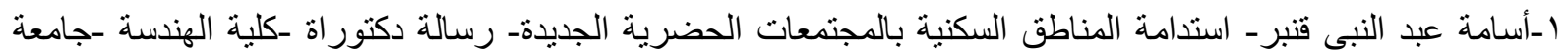

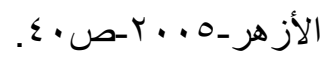

1-Osma Abdelnaby Kenber, Astedamet elmnatek elskanya belmogtma3at el7adrya elgadeda, resalet doctorah, kollyat elhandasa, gama3t elazher 2005.

ז-إيهاب محمود عقبة- أسس ومعايير التصميم المستدام للمناطق الخضراء- بحث منشور - كلية الهندسة - جامعة الفيوم -

2-Ehab Ma7moud 3okba, Osos wa ma3ayer eltasmem llmnatek elkhadra2, ba7s manshour, kolyat el handsa, game3at elfayoum, 2015.

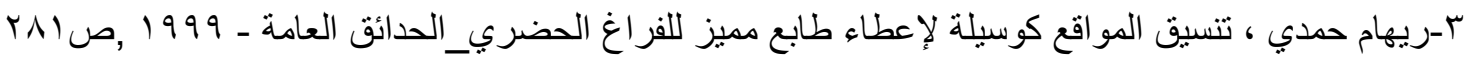
3-Reham Hamdy, Tansek elmoake3 kwasela le3ta2 tabe3 momayaz llfra3' el7adary, el7adaek el3ama, 1999.

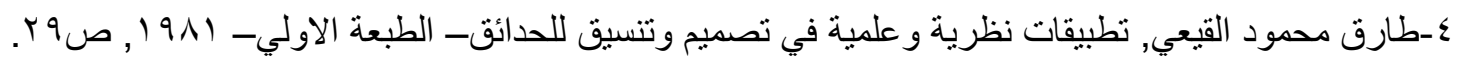
4-Tarek Mahmoud elke3y, Tatbekat nazarya wa 3elmya fi tasmem el 7daek, Tab3a ola, 1981. ه-عبد الحميد عبد الواحد, مقدمة في تخطيط وتصميمم المناطق الخضر اءهاء وفر اغات البيئة العامة في المدن , دار غريب

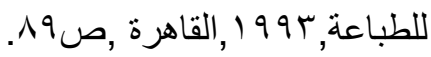
5-Abdelhamed Abdelwa7ed, mokadema fi takhtet wa tasmem elmnatek elkhadrea2 wa fra3'at elbe2a el3amafi elmodon, Dar ghareb llteba3a,1993.

T-عصام الدين محمد على - تضمين مبادئ الإستدامة الثشاملة في التصميم الحضري ـ مجلة العلوم الهندسية ـ كلية

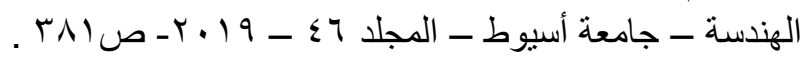

6-3esam eldeen mohamed ali, Tadmen mbade2 elestedama elshamela fi eltasmem el7adary, megalet el3loom elhandasya, kolyat elhandsa,2019.

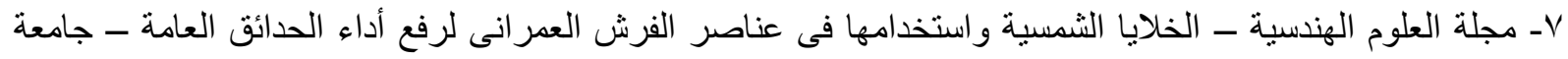

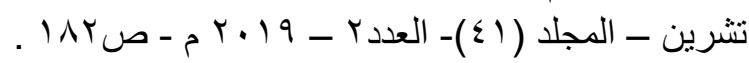
7-Megalet el3loom wa elhandsa, elkhalaya elshamsya wa estkhdmha fi 3naser elfarsh el3omrany lrfe3 ada2 elfdaek el3ama, game3t teshreen,2019.

1ـ هبه الله عثمان، التجميل البيئي المستدام في المناطق الأثرية، بحث منشور ، مجلة العمارة والفنون و العلوم الإنسانية،

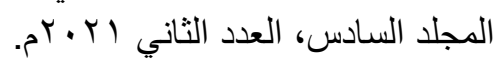

8-Hebaetallah Othman, eltagmel elbe2e elmostadam fi el mnatek elasrya, ba7s manshour, megalet el3omara wa elfnon wa el3loom elensanya, elmoglad 6,3add 2, 2021. 


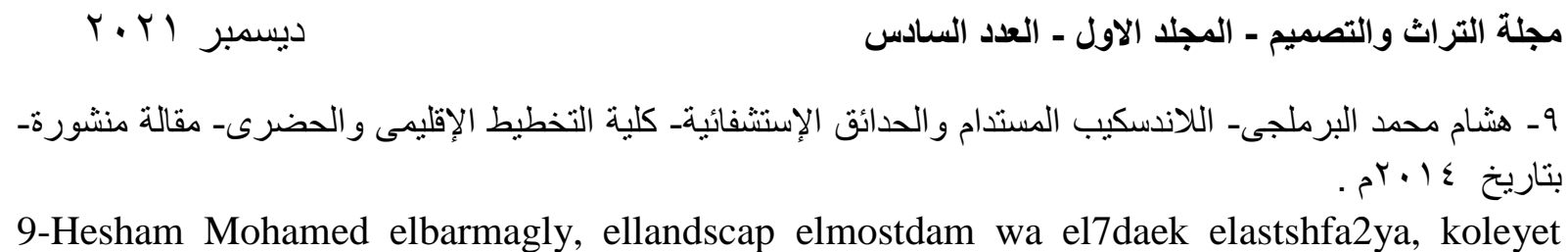
eltakhtet eleklemy wa el7adaery, 2014.

• 1 - صابر,احمد. " مرونة التشريعات البنائية كأحد عوامل الارتقاء ببيئة الابداع المعماري" مجلة العمارة و الفنون و العلوم الإنسانية المجلد 7 العدد العرائ

10- sabir ahmad. "mrunat tashrieat albina' ka'ahad eawamil aliartiqa' bibiyat al'iibdae almiemari" majalat aleimarat walfunun waleulum al'iinsaniat almujalad 6 aleadad 27

11-Amitai Etzioni, Reconstruction: An Agenda, Journal of Intervention and State Building, Volume 1, March 2007.

12- Bernard Feilden, Conservation of Historic Buildings, Butterworth and Co., LTD,England, 1982.

12-Gray Bridge, Sophie Watson, A Companion to The City, Blackwell Publishers Ltd,United Kingdom, 2003.

13-H. David, Refurbishment and Upgrading of Buildings, E \& FN Spon, London,England, 2005.

14-J. Strike, Architecture in Conservation - Managing Development at Historic Sites, Routledge, London, 1994.

15-Robert Garland Thomson, Authenticity and The Post-Conflict Reconstruction of Historic Sites, CRM: The Journal of Heritage Steward Ship Home, Volume 1-8,2008.

16- http://whc.unesco.org/heritage.htm. 